Portland State University

PDXScholar

\title{
Effects of Insulin, Sodium and D-Glucose on Amino Acid Absorption in the Intestine of Rats
}

Andre-Gerard Craan

Portland State University

Follow this and additional works at: https://pdxscholar.library.pdx.edu/open_access_etds

Part of the Biochemistry, Biophysics, and Structural Biology Commons, Biology Commons, and the Organismal Biological Physiology Commons

Let us know how access to this document benefits you.

\section{Recommended Citation}

Craan, Andre-Gerard, "Effects of Insulin, Sodium and D-Glucose on Amino Acid Absorption in the Intestine of Rats" (1971). Dissertations and Theses. Paper 1449.

https://doi.org/10.15760/etd.1448

This Thesis is brought to you for free and open access. It has been accepted for inclusion in Dissertations and Theses by an authorized administrator of PDXScholar. Please contact us if we can make this document more accessible: pdxscholar@pdx.edu. 
AN ABSTRACT OF THE THESIS OF Andre-Gerard Craan for the Master of Science in Biology preserted June 4, 1971.

Title: Effects of Insulin, Sodium and D-Glucose on Amino Acid Absorption in the Intestine of Rats.

APPROVED BY MEMBERS OF THE THESIS COMMITTLE:

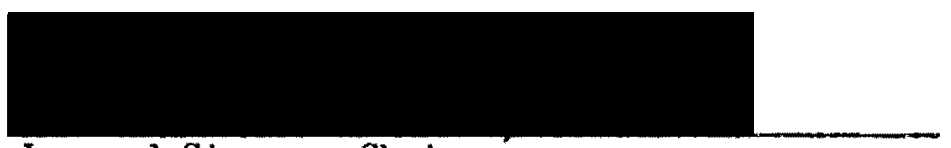

Leonard Simpson, Chairman

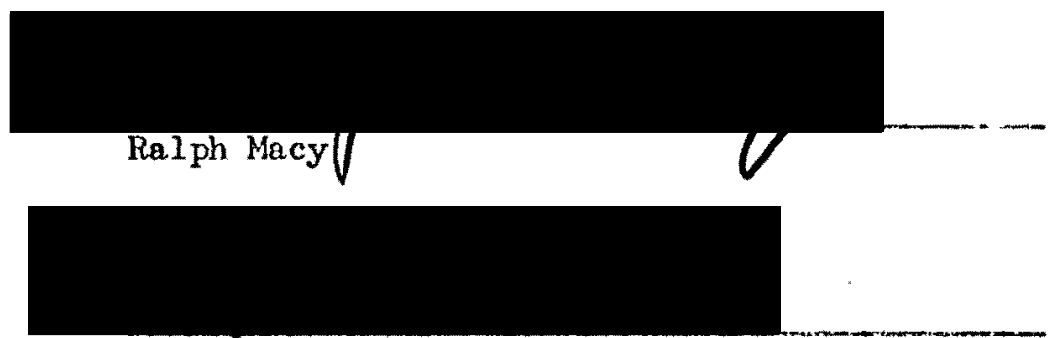

Malcolm Lea

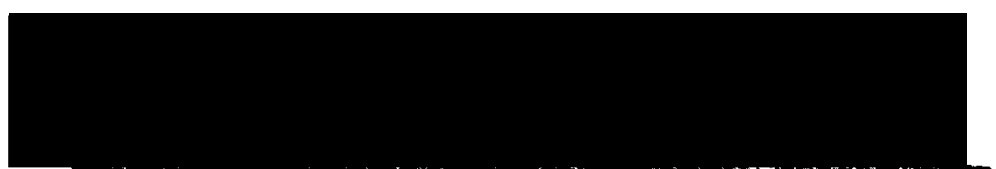

Richard Tocher

Amino acid absorption across rat intestine in vitro was inhibited or stimulated by insulin depending on the hormone serosal concentration.

The absence of sodium ions from the inculating solution resulted in a significant decrease of L-alanine absorption. However, L-alanine absorption was enhanced in a sodium-free medium by the addition of insulin on the serosal side of the intestine.

A sizable decrease in L-alanine and L-lysine absorption was produced by introduction of D-glucose ( $0.2 \%$ and $2 \%)$ in the Krebs-Ringer's incubating buffer. Nevertheless, the presence of D-glucose did not prevent the stimulatory effect of insulin on amino acid absorption. 
EPPDCTS OP INSULIN, SODIUM AND D-GLUCOSE

ON AMINO ACID ABSORTPION IN THE

TNIESTINE; OF IATS

by

ANDRE-GERARD CRAAN

A thesis submitted in partial fulfillment of the requirements for the degree of

MASTER OF SCIENCE

in

BIOLOGY

Portland State University 1971 
TO THE OFFICE OF GRADUATE STUDIES:

The members of the Committee approve the thesis of Andre-Gerard Craan presented June 4, 1971.

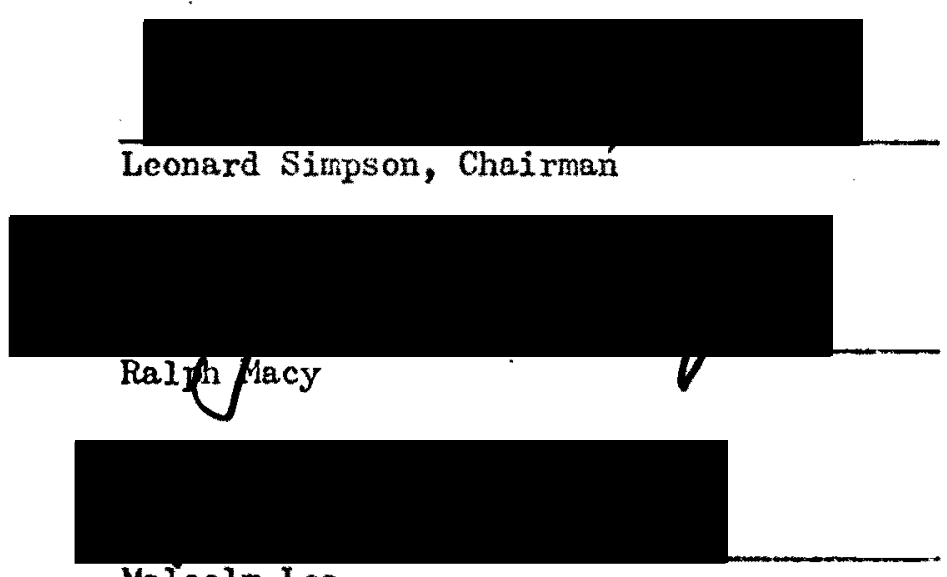

Malcolm Lea

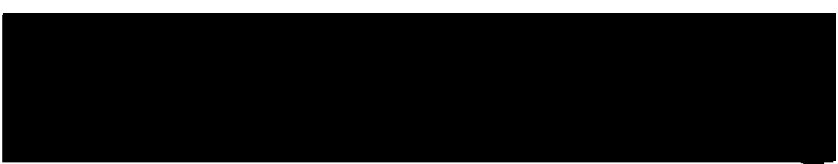

Richard Tocher

APPROVED:

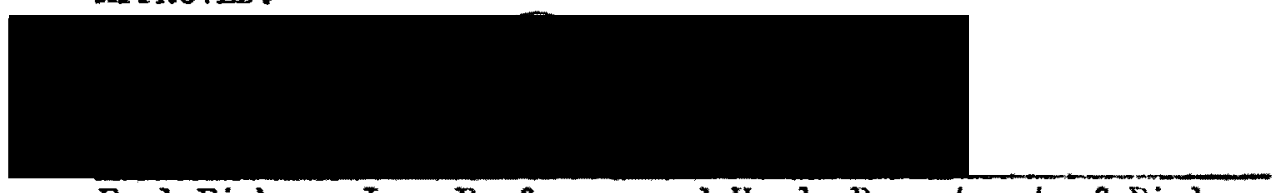

Earl Fisher, Jr., Professor and Head, Department of Biology

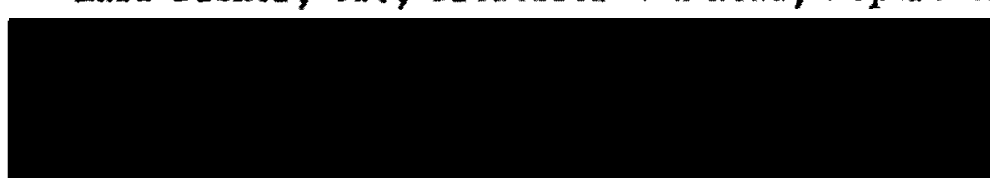

Darid Clark, Dean of Graduate Studies

June, 1971 


\section{ACKNOVLEDGMENTS}

The author wishes to thank Dr. Leonard Simpson, as his research supervisor and thesis adviser, for his guidance throughout this entire work; Dr. Richard D. Tocher for providing him with the techniques and the apparatus necessary for liquid scintillation counting; Dr. Quentin D. Clarkson for his suggestions in the statistical analysis of the data; the Biology Department of Portland State University for the financial help in purchasing $\mathrm{c}^{14}$ - labeled chemicals that were used in the experiments. This study was primarily supported by National Science Foundation Grant GB-16732 to Drs. Leonard Simpson and Clyde Calvin. 
TABLE OF CONTENTS

PAGE

ACKNOHLEIGGMENTS . . . . . . . . . . . . . . . . . .

LIST OF TABLES

$\nabla$

LIST OF FIGURES

$\nabla i \mathbf{i}$

IN'RRODUCTION

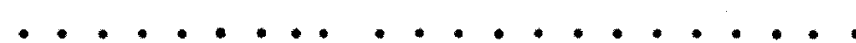

1

MATERIALS

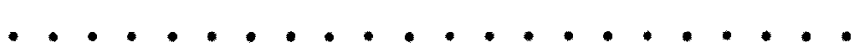

4

METHODS

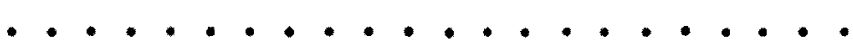

RESULTS

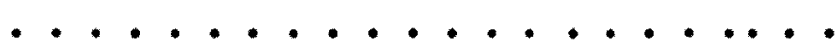

Amino Acid Absorption along the Intestine .....

Effects of Insulin on L-Alenine Absorption .....

L-Alanine Absorption in Sodium-Free Mediun . . . .

D-Glucose and Amino Acid Absorption . . . . .

Error Analysis .................

DISCUSSION

CONCLUSION

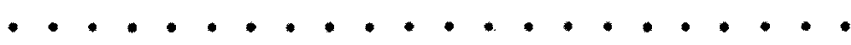


LIST OF TABLES

TABLE

PAGE

I Number and Dimensions of Structures Involved in Intestinal Absorption ............

II Variations in the Absorption of L-Alanine along the

Small Intestine of Sexually Mature Rats . . ค 16

III Amino Acid Absorption in the Three Main Segments of

the Small Intestine of Sexually Mature

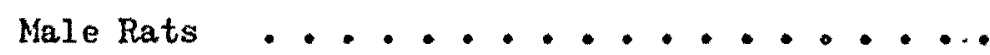

IV Absorption of Im-Alanine in the Three Main Segments of

the Small Intestine of Sexually Immature

Rats

$\checkmark$ Effects of Insulin on ImAlanine Absorption in

Sexually Mature Male Rats .........

VI Effects of Insulin on L-Alanine Absorption in

Sexually Immature Male Rats .........

VII Effects of Sodium and/or Insulin on L-Alanine

Absorption in Sexuelly Mature

Male Rats ................

VIII Effects of D-Glucose (2.0\%) and/or Insulin on

L-Lysine Absorption in Sexually

Mature Male Rats .............. 
IX Effects of D-Glucose $(0.2 \%)$ and/or Insulin on

L-Alanine Absorption in Sexually

Mature Male Rats .............

X Dry Weights of Intestinal Segnents of a Sexually

Mature and a Sexually Imnature Rat ...... 
LIST OF FIGURES

FIGURE

PAGE

1 Insulin Effects on L-Alenine Absorption in Sexually Mature Male Rats (Duodenum) . . . . . 22

2 Insulin Effects on L-Mlanine Absorption in Sexually Mature Male Rats (Jejunur) ........ 23

3 Insulin Effects on L-Alenine Absorption in Sexually Mature Male Rats (Ileum) ......... 24

4 Insulin Effects on L-Alanine Absorption in Sexually Immature Male Rats (Duodenum) . . . . . 26

5 Insulin Effects on L-Alanine Absorption in Sexually Immature Male Rats (Jejunurn) ....... 27

6 Insulin Effects on L-Alanine Absorption in Sexually

Immature Male Rats (Ileum) . . . . . . 28

$7 \quad$ Liquid Scintillation Counting Efficiency as a

Function of Channel Ratio ......... 51 


\section{INTRODUCTION}

Amino Acid Absorption in the Small Intestine. Stomach enzymes attack only a small amount of the protein of the diet. Thus, a mixture of undigested protein with products of peptic digestion ranging from large polypeptides to a fer free amino acids is delivered to the intestine es the protein portion of the diet. As a result, the major part of protein digestion must take place in the intestine (1).

Pancreatic enzymes (trypsin, chymotrypsin, carboxypeptidase) that are released into the intestinal lumen through pancreatic ducts hydrolyze some proteins to amino acids. However, most of the products of such hydrolyses are dipeptides and small polypeptides (2).

Enzymes (amino polypeptidases and dipeptidases) located in the epithelial cells of the small intestine break the undigested dipeptides and small polypeptides into amino acids (3). The latter then pass into the blood stream.

Amino acid absorption is an active transport process supported by oxidative metabolism in the mucosa $(2,4)$. As an active transport process, amino acid absorption may overcome the sum of the forces of diffusion, electrical field and solvent drag (5), and thus may go against a concentration gradient $(6,7)$.

Insulin and Amino Acid Absorption. The hormone insulin has been the subject of many speculations and numerous investigations. Since it was found to alleviate diabetes $(8,9,10,11)$, medical physiologists and biochemists have oriented their research intersts, for the most part, toward its effects on blood sugar level. As a result, the literature is rich in studies of insulin effects on the intestinal absorption of carbohydrates and especially of glu- 
cose.

Compared to the vast literature concerning the effects of insulin and the effects of diabetes on the intestinal absorption of glucose, there has been very little work on the effects of insulin on intestinal amino acid absorption.

Insulin has been found to stimulate transfer of the non-metabolizable amino acid, a-aminoisobutyric acid, from extracellular to intracellular space in rat diaphragm $(12,13)$. However, the results are different for natural metabolizable amino acids. Manchester and Young (13), and Wool and Krahl (14), indeed, found no effect of insulin on the accumulation of L-amino acids in the same tissue. Manchester and Krahl (15) found that insulin can promote amino acid incorporation into protein. A similar conclusion was reached for rat adipose tissue (16). This stimulatory action of insulin appears not to depend on its simultaneous enhancing action on amino acid transport $(15,17)$.

The preceding investigations were centered more on amino acid incorporation into tissue protein than its actual transport into tissues. However, in a paper that dealt specifically with the effect of insulin on intestinal absorption Fromm et al. (18) denied any effect of insulin on Lmalanine transfer by rabit ileum in vitro.

Sodium and Amino Acid Absorption. Attention has been focused on sodiun in absorption phenomena since it was discovered that membrane resting potential was changed as $\mathrm{Na}^{+}$moved in and out of myelinated fibers (19), the giant axon of the squid (20), and striated muscle fibers of frogs (21). These and other investigations $(22,23,24)$ led to the idea of a sodium pump functional in membrane transport phenomena. The sodium pump is an energydependent system that transports sodiun ions across cell membranes and 
creates an electrochemical potential difference between intracellular and extracellular fluids.

It was not until the end of the $1950^{\prime} \mathrm{s}$ that studies were made on the influence of $\mathrm{Na}^{+}$on the intestinal absorption of amino acids. It has been found that a decrease in $\mathrm{Na}^{+}$concentration in the medium causes a parallel decrease in amino acid transfer $(25,26,27)$. However, Adibi's findings (28) do not support such a general conclusion.

Carbohydrates and Amino Acid Absorption. There appears to be no one unifying principle as to the role of carbohydrates on amino acid transfer across the intestine. Several workers $(29,30,31,32,33)$ have found that glactose inhibits amino acid transport. Mannose is reported to have no effect (34), and reports are contradictory in regard to the effect of fructose on amino acid transport $(33,34)$.

Previous workers have disagreed on the role of glucose in the absorption of amino acids. In the words of Hardcastle et al. (29), "the reported effects of $\mathrm{D}$-glucose vary from inhibiton $(33,35)$ to stimulation $(32,34,36)$ or even no effect (37)." These investigations on D-glucose were all conducted using rat small intestine. 


\section{MATERIALS}

L-alanine-c $c^{14}(U)$, L-lysine- $C^{14}(U)$ and $\alpha$-aminoi sobutyric-1-C $C^{14}$ acid (New Fingland Nuclear) were each diluted separately in $0.01 \mathrm{~N} \mathrm{HCl}$ to make stock solutions with a final concentration of 5 microcuries per milliliter. Specific activities were 123 millicuries per millimole for L-alanine, 255 millicuries per millimole for L-lysine and 7.99 millicuries per millimole for $\alpha$-aminoisobutyric acid.

To start each experiment, 20 to 60 microliters of the stock solution of one of the amino acids, corresponding to an activity of 0.1 to 0.3 microcurie, were transferred by microliter syringe to 7.5 milliliters of KrebsRinger's bicarbonate buffer which served as the incubating medium.

The composition of the Krebs-Ringer's bicarbonate buffer is as follows $(38)$ :

100 parts $0.90 \% \mathrm{NaCl}$

4 parts $1.15 \% \mathrm{KCl}$

3 parts $1.22 \% \mathrm{CaCl}_{2}$

1 part $2.11 \% \mathrm{KH}_{2} \mathrm{PO}_{4}$

1 part $3.82 \% \mathrm{MgSO}_{4} \cdot 7 \mathrm{H}_{2} \mathrm{O}$

21 parts $1.30 \% \mathrm{NaHCO}_{3}$.

Sodium ions were replaced with potassium in some experiments. In these experiments, the bicarbonate buffer was made in the same proportion as shown in the table above, except that $\mathrm{NaCl}$ and $\mathrm{NaHCO}_{3}$ were replaced by $\mathrm{KCl}$ and $\mathrm{KHCO}_{3}$ on a percentage $(\mathrm{k} / \mathrm{v})$ basis. For the study of D-glucose effects on amino acid absorption, D-glucose was added to the incubating Krebs-Ringer's 
bicarbonate solution at concentrations of $0.2 \%$ and $2 \%(\mathrm{v} / \mathrm{v})$.

Fresh solutions of insulin with a concentration of 20 units per milliliter in $0.01 \mathrm{~N} \mathrm{HCl}$ were prepared from crystalline bovine insulin $(26 \mathrm{U} / \mathrm{mg}$, CalBiochem) pricr to each set of experiments. All solutions were stored in the cold and used within 3 days of preparation. 


\section{METHODS}

\section{The Bverted-sac Technique}

Sexually mature male Fischer/344 rats (Simonsen Laboratories, Gilroy, California), weighing 160-250 grams and ranging in age between 4 and 8 months, were kept on a 12 hours light-12 hours dark cycle. They were fasted 30-40 hours before they were sacrificed, after ether anesthesia, by a sharp blow on the head. The small intestine was dissected free and flushed thoroughly with saline unitl it became clean. The intestine was immediately turned inside out (39), placed in Ringer's solution and divided into $6 \mathrm{~cm}$ length sacs.

The sacs were identified as duodenal, jejunal and ileal sacs. They were incubated in a chilled Krebs-Ringer's solution that had been gassed with $95 \% \mathrm{O}_{2}-5 \% \mathrm{CO}_{2}$. This procedure (Olsen and Rosenberg) was used in order to insure the viability of the intestinal tissue (40). The 0lsen-Rosenberg technique was modified for about $10 \%$ of the experiments in which the intestinal sacs were left in normal saline exposed to the air at room temperature until they were used for absorption experiments. The period of maintenance in normal saline at roon temperature varied from 2 to 40 minutes. No significant difference in amino acid absorption was noted between these tissues and the tissues that were given the 0lsen-Rosenberg treatment.

Each everted experimental sac was filled with 0.5 to 5 units of insulin in $0.01 \mathrm{~N} \mathrm{HCl}(20 \mathrm{Units} / \mathrm{ml})$ made up to $0.75 \mathrm{cc}$ with Krebs-Ringer's solution. An equal volume of $0.01 \mathrm{~N} \mathrm{HCl}$ was added to the Krebs-Ringer's solution that was introduced into each control sac. 
Individual sacs with a serosal volume of $0.75 \mathrm{cc}$ were ligated at both ends, then incubated in $50 \mathrm{cc}$ Erlenmeyer flaslss containing $7.5 \mathrm{cc}$ of KrebsRinger's solution and $\mathrm{C}^{14}$-amino acid. The flask was gassed with a mixture of $95 \% \mathrm{O}_{2}-5 \% \mathrm{CO}_{2}$ and placed in a $37^{\circ} \mathrm{C}$ shaker-incubator with a platform rotating at a speed of 130-150 revolutions per minute. Incubation lasted 55 minutes. Similar preparations were made from sexually immature rats (3-4 weeks old, weighing 50-70 grams), except their fast lasted 6-12 hours; their intestinal sacs were cut $6 \mathrm{~cm}$ long; $6 \mathrm{ml}$ Krebs-Ringer's bicarbonate buffer was used as the mucosal volume and $0.5 \mathrm{ml}$ as the serosal volume.

\section{Collection of Samples}

After incubation, each intestinal segment was dried on paper towel. Its content, representing the serosal volume, was poured into a glass vial. The incubating Krebs-Ringer's buffer of the flasl constituted the mucosal volume.

\section{Liquid Seintillation Counting}

Radioactive measurements were taken of $0.30 \mathrm{ml}$ aliquots of serosal and of mucosal solutions. The aliquots were diluted in a scintillation solvent that was composed of toluene, absolute alcohol, 2,5-diphenyloxadole (PPO) and p-bis 2-(5-phenyloxazolyl) (POPOP). A volume of $15 \mathrm{ml}$ of the scintillation solvent was mixed with each $0.30 \mathrm{ml}$ aliquot producing a sample consisting of $63.6(\mathrm{v} / \mathrm{v})$ toluene, $34.4 \%(\mathrm{v} / \mathrm{v})$ ethanol, $2.0 \%(\mathrm{v} / \mathrm{v})$ water, $0.40 \%$ $(w / v)$ PPO and $0.01 \%(w / v)$ POPOP $(0.01 \%)$. The liquid composition of the soIution is well within the range of mutual solubility of toluene, ethanol and water (41).

A solubility test was run on the scintillation solvent and an aqueous sample. The test consists of counting volumes of $\mathrm{c}^{14}$-aqueous samples 10.05 
$\mathrm{ml}, 0.10 \mathrm{ml}, 0.20 \mathrm{ml}$ and $0.30 \mathrm{ml}$ ) diluted in $15 \mathrm{ml}$ of scintillation

solvent and comparing the different counts. Theoretically, the disintegration rate of $0.10 \mathrm{ml}$ of sample should be twice that of $0.05 \mathrm{ml}$, half as large as that of $0.20 \mathrm{ml}$ and a third of that of $0.30 \mathrm{ml}$. $\Lambda$ difference of $0.48-1.32 \%$ was noted between the DIM (disintegrations per minute) of $0.01 \mathrm{ml}$ of sample and that of other samples (multiplied by their proper factor) due to solubility error produced by the non-uniformity of the sample in the scintillation solvent. Such a small factor would not alter the results.

\section{Calculations}

Expression of Amino Acid Concentration. Amino acid concentration was expressed in terms of the number of disintegrations per minute (DFM) in a $0.30 \mathrm{ml}$ aliquot of the sample. The DPM represents a truer concentration figure than the counts per minute (CPM) in view of the fact that the CPM varies with the relatively variable efficiency of the counts. For example, it would be wrong to think that a solution of 25,015 counts per minute with a counting efficiency of 0.75 has the same $C^{14}$-amino acid concentration as a solution of $25,015 \mathrm{CPM}$ with an efficiency of 0.80 . Their respective disintegration rates are given by the following formula:

$\mathrm{DPM}=\frac{\mathrm{ClM}^{\text {sample }}-\mathrm{CPM}^{\text {background }}}{\text { counting efficiency }}$, that is, $\mathrm{DPM}=\frac{20,015-15}{0.75}=26,666 \mathrm{DPM}$ in the first sample and DPM $=\underline{20,015-15}=25,000 \mathrm{DPM}$ in the second sample. With a difference of the size of 1,666 DPM or $6.2 \%$, it can be concluded the samples do not"have the same amino acid concentration.

The background is a non-radioactive mixture of $97 \%$ scintillation solvent and 3\% Krebs-Ringer's buffer. The purpose of subtracting a background from the count of the sample is to account for a fev counts (usually 
averaging $15 \mathrm{CPM}$ ) due to noises, queuching effects and other factors which are present in the counter.

The channel-ratio method gives the counting efficiency of the samples. This method uses the inverse proportionality of efficiency to the ratio of the $B$ channel over that of the $C$ channel of the counter. Efficiency is read as the ordinate of the graph shown in the appendix. An alternate and more accurate method of obtaining counting efficiencies is the internal standardization method. This involves the use of standard $\mathrm{C}^{14}$-toluene of known disintegration rate. The closeness of the measurements from the two different methods is a function of the performance of the liquid scintillation counter. The instrument, after being tested for its performance, showed an average difference of $1.45 \%$ between the two efficiencies. Such a difference was due to mechanical errors in the performance of the counter added to pipetting errors. A further check on the performance of the counting apparatus consists of evaluating the counts. The repeatability of the counts for the same sample is a sign of good performance and proper operation in the machine. Following the steps outlined in a Packard Operating Manual (42), a sample was counted thirty times. $66.66 \%$ of the counts fell within the range of the average plus or minus the square root of the average. This is more than the minimum $66 \%$ that is required for good performance in the counter. Expression of the Effects of Chemical Agents. Amino acid transfer from mucosa to serosa was expressed as the ratio of the amino acid concentration on the serosal side (S) over that on the mucosal side (M) at the end of a 55 minutes incubation period. Amino acid uptake in two different segments of the intestine could then be compared on the basis of their S/M ratio. Amino acid uptake averaged approximately $9 \%$ of the initial counts. About 1.5\% was lost into the intestinal tissue. 
The effects of insulin, sodium or D-glucose on amino acid absorption were expressed by subtracting algebraically the $S / M$ ratio of control sacs from that of experimental sacs. A positive number, indicating a positive effect of a given physiochemical agent, resulted from such a subtraction when the absolute value of the experimental was greater than that of the control. There was a negative effect, designated by a negative value for the difference, when the absolute value of the experimental was less than that of the control. The ordinate axes of the graphs in Figures 1, 2, 3, 4, 5 and 6 represent scales of "effects on absorption." The zero lines on these scales were determined by the controls.

Because of unequal absorption rates in the three main parts of the small intestine and because of differences between individual organisms, these subtractions were carried out between experimental and control sacs of the same intestinal segment taken, whenever possible, from the same rat (duodenum, jejunum or ileum).

\section{Histological Procedures}

In order to study histological differences among the three main intestinal segments, 10 micron thick transverse sections of the small intestine of male rats were prepared. They were fixed in Bouin's fluid, stained with Harris' alum hematoxylin and counterstained with eosin $Y$. They were examined under a microscope provided with a calibrated micrometer.

The number of villi per $10 \mu$ transverse section was counted; the distance from the villi base to the internal border of the serosa was measured and the surface area of the villi was calculated using the formula $S=\pi D\left(h+\frac{D}{4}\right)$ 
S: surface area

$\pi: \quad 3.1416$

D: diameter of (cylindrical) villi

$h$ : height of (cylindrical) villi.

The equation represents the lateral surface area of a cylinder ( $\pi \mathrm{Dh}$ ) plus the surface area of one base of the cylinder $\left(\frac{\pi D^{2}}{4}\right)$. 


\section{RESULTS}

\section{Amino Acid Absorption along the Intestine}

\section{Histological Considerations}

A factor that was of great importance in the interpretation of the results was the non-uniformity of absorption along the intestine. A histological study conducted at the light microscope level (Table I) showed regional differences in total surface available for absorption along the length of the small intestine and in the thickness of the intestinal wall components of possible significance.

Structures Exposed to the Intestinal Lumen. According to the relation, transport rate $=$ surface area $x$ flux, at a given flux value, a larger exposed area makes for a more rapid transport rate (43). Since villi are responsible for increasing the number of epithelial cells exposed to the lumen (43), differences in their occurrence elong the small intestine constitute a legitimate morphological basis for comparing transport rate in the duodenum, the jejunum and the ileum.

Villi are most numerous in the ileum, less numerous in the duodenum and fewest in the jejunum (Table I). A histological examination of the mucosa revealed a uniform distribution of the villi in the duodenum and the upper jejunum. In the ileum, clusters of villi were randomly interrupted with lymph nodules. Villi were generally taller and wider in the jejunum. The number, the height, the diameter of the villi and the surface area of the average villus were included in a comprehensive value: the mean surface area of villi per transverse section (Table I). 
On the basis of surface area of villi alone, absorption would be expected to be higher in the duodenum and the jejunum and lover in the ileum (Table I).

Other structures that may cause differences in absorption rate along the intestine are the plicae circulares. They form in the submucosa, pass through the muscularis mucosae and extend to the mucosa. Their occurrence in the small intestine was not determined in this study.

Structures not Exposed to the Intestinal Lumen. The non-mucosal parts of the intestine, namely the muscularis and the tunica serosa, are at least passively involved in transfer as measured by the everted-sac technique. The thickness of these layers should influence transport rates in that passage through these layers should vary inversely with the thickness of the tissue. The average width of the muscularis plus the serosa is about $147 \mu$ in the ileum, $158 \mu$ in the jejunum and $163 \mu$ in the duodenum (Table I). These numbers alone imply that passage through the layers that are not exposed to the lumen should increaseslightly from duodenum to jejunum to ileum. It is evident that the results obtained from the calculation of the mean surface area of villi per section and from the measurements of the width of the muscularis plus the serosa suggest that these two factors would be expected to have opposite effects on relative transport rates in the three regions of the intestine. 
TABLIE I

NUMBER AND DIMENSIONS OF STRUCTURES INVOLVED IN ABSORPTION

IN INTESTINAL SEGMFNTS

\begin{tabular}{|c|c|c|c|}
\hline & Duodenum & Jejunum & Ileum \\
\hline $\begin{array}{l}\text { Number of villi per } \\
\text { cross-section }\end{array}$ & 29 & 26 & 37 \\
\hline $\begin{array}{l}\text { Number of sections counted } \\
\text { for villi }\end{array}$ & 6 & 6 & 7 \\
\hline Villi height & $389 \mu$ & $393 \mu$ & $296 \mu$ \\
\hline Villi diameter & $117 \mu$ & $127 \mu$ & $68 \mu$ \\
\hline $\begin{array}{l}\text { Surface area of the } \\
\text { average villus }\end{array}$ & $0.1537 \mathrm{~mm}^{2}$ & $0.1611 \mathrm{~mm}^{2}$ & $0.0671 \mathrm{~mm}^{2}$ \\
\hline Number of villi measured & 15 & 14 & 17 \\
\hline $\begin{array}{l}\text { Mean surface area of villi } \\
\text { per cross-section }\end{array}$ & $4.4595 \mathrm{~mm}^{2}$ & $4.3969 \mathrm{~mm}^{2}$ & $2.4824 \mathrm{~mm}^{2}$ \\
\hline $\begin{array}{c}\text { Average width of muscularis } \\
+ \text { serosa }\end{array}$ & $163 \mu$ & $158 \mu$ & $147 \mu$ \\
\hline Number of sections & 21 & 12 & 19 \\
\hline
\end{tabular}


Regional Differences in Intestinal Absorption

In order to study apbsorption differences along the small intestine, a series of experiments using the everted-sac procedure were repeated with $16 \mathrm{~cm}$ segments. The incubating solution was a Krebs-Ringer's bicarbonate buffer containing L-alanine without insulin, glucose or any other physiological agent. It was found that, in general, within each main division of the intestine, the $S / M$ ratios differed from each other by relatively close margins. But $S / M$ values obtained from duodenal segments were markedly different from those of jejunal or ileal sacs (Table II). ${ }^{1}$

Absorption differences anong selected $6 \mathrm{~cm}$ intestinal sacs were also studied. Measuring from the pyloric cecum, a series of sacs were made starting at a distance of $7-8 \mathrm{~cm}$ (second duodenal sac), 25-26 cm second jejunal sac) and 49-50 $\mathrm{cm}$ (second ileal sac).

It was observed that the first duodenal and the last two ileal sacs were located in region of low amino acid absorption. Their S/M ratios are reported separately in Table II. The first duodenal sac showed the lowest $S / M$ ratio. The $S / M$ ratio in the lower ileum was lower than those of the jejunum and upper ileum. These facts were taken into account in the calculation of the effects of physiochemical agents on absorption by comparison between experimental and control results. An experimental from the first sac of the duodenum of a given rat, for example, was compared with a control taken from the upper duodenum of another rat of nearly equal weight and age. Experimental and control sacs from lower ileum were also compared with each other for the estimation of the effects of physiochemical agents on absorption. 
TABLE II

VARIATIONS IN THE ABSORPTION OF L-ALANINE

ALONG THE SMALL INTESTINE OF A

SEXUALLY MATURE MALE RAT

\begin{tabular}{|c|c|c|c|}
\hline Intestinal parts & $\begin{array}{l}\text { Positional order of } \\
\text { intestinal sacs }\end{array}$ & Final & $S / M^{*}$ \\
\hline Duodenum & 1 & & 0.29 \\
\hline Duodenum & 2 & & 0.51 \\
\hline Duodenum & 3 & & 0.59 \\
\hline Je junum & 4 & & 0.70 \\
\hline Je junum & 5 & & 0.59 \\
\hline Jejunum & 6 & & 0.74 \\
\hline Jejunum & 7 & & 0.66 \\
\hline Jejunum & 8 & & 0.88 \\
\hline Ileum & 9 & & 1.37 \\
\hline Ileum & 10 & & 0.89 \\
\hline Il eum & 11 & & 1.02 \\
\hline Ileum & 12 & & 1.37 \\
\hline Ileum & 13 & & 0.81 \\
\hline Ileum & 14 & & 1.18 \\
\hline Ileum & 15 & & 0.65 \\
\hline Ileum & 16 & & 0.54 \\
\hline
\end{tabular}

* $S / M=\frac{\text { serosal } C^{14} \text { concentration }}{\text { mucosal } C^{14} \text { concentration }}$ initial $S / M$ ratios vere 0. 
The results shown in Table III represent the mean values of the $\mathrm{S} / \mathrm{M}$ ratios of these sacs. They indicate that amino acid transfer from mucosal side to serosal side is greater in the ileum and jejunum than the duodenum. In an attempt to compare amino acid absorption between adult and sexually immature rat intestines, similar experiments were conducted with L-alanine using young male rats. The results followed the same trend as for the adults, namely that the absorption rate of L-alanine is higher in the ileum and the jejumum and lower in the duodenum(Table IV). 
TABLE III

AMINO ACID ABSORPIION IN THE THREE MAIN

SEGMENTS OF THE SMALL INTESTINE IN

SEXUALLY MATURE RATS

Duodenum

Jejunum

Il eum

L-alanine

Final* $S / M \pm S . E^{* *}$

$0.58 \pm 0.04$

$0.76 \pm 0.04$

$0.83 \pm 0.04$

Number of experiments

18

18

18

Standard deviation

0.11

0.18

0.26

$\mathrm{P}$ (duodenum vs jejunum and/or il eum) $* * *$

$\leqslant 0.005$

L-1ysine

Final* $S / M \pm S . E . * *$

$0.49 \pm 0.05$

$0.63 \pm 0.05$

$0.63 \pm 0.05$

Number of experiments

3

3

2

Standard deviation

0.003

0.16

0.04

$\mathrm{P}$ (duodenum vs jejunum and/or ileum) $* * *$

$<0.1$

a-aminoisobutyric acid

Final* $S / M^{* *}$

Number of experiments
0.56

0.57

0.63

1

1

* Initial S/M ratios were 0 .

** $S / M \pm S . E .=\frac{\text { serosal } C^{14} \text { concentration }}{\text { mucosal } C^{14} \text { concentration }}$ standard error.

*** $\mathrm{P}=$ significance of the difference between the sample means of the duodenum and those of the other two intestinal segments, based on the leastsignificant-difference test $(44,45)$. 
TABLE IV

ABSORPTION OF L-ALANINE IN THE THPRE MATN

SEGMIJNTS OF THE SMALL INTCSTINE OF

SEXUALLY IMMATURE RATS

\begin{tabular}{lccc}
\hline & Duodenum & Jejunum & Il eum \\
\hline Final* S/M S.E.** & $0.66 \pm 0.08$ & $0.89 \pm 0.08$ & $0.90 \pm 0.08$ \\
Number of experiments & 6 & 7 & 7 \\
Standard deviation & 0.10 & 0.19 & 0.29 \\
$\begin{array}{l}\text { P (duodenum vs jejunum } \\
\text { and/or il eum)*** }\end{array}$ & 0.05 & \\
\hline
\end{tabular}

*Initial S/M ratios were 0.

$*{ }^{*} S / M \pm S . E .=\frac{\text { serosal } C^{14} \text { concentration }}{\text { mucosal } C^{14} \text { concentration }}$ standard error.

***P $=$ significance of the difference between the sample means of the duodenum and those of the other two intestinal segments, based on the leastsignificant-difference test $(44,45)$. 
Effects of Insulin on L-Mlanine Absorption

An important purpose of this study was to determine the dose-response effect for insulin with regard to L-alanine transfer through the intestinal wall.

Effects of Insulin on Absorption in Sexually Mature Rats. The effects of insulin on L-alanine absorption in the small intestine of sexually mature male rats vary from inhibition at concentrations in the neighborhood of 0.5 unit per $0.75 \mathrm{ml}$ of serosal volume to stimulation at $3.0-3.5$ units where maximum absorption is observed. At higher concentrations, the response is highly variable (Table V).

Figures 1, 2 and 3 represent graphs of the effects of insulin on L-alanine absorption versus its concentration. They show insulin effects in the duodenum, the jejunum and the ileum respectively.

Effects of Insulin on Absorption in Sexually Immature Rats. The graph of insulin effects versus its concentration in sexually immature rats has a similar shape to that of adult rats. 'The main difference between the two kinds of graphs lies in the concentrations corresponding to positive effects of insulin. In the sexually immature male rats, the peak of the graph is displaced toward the left. Maximum effect of insulin in these rats is observed at a concentration of 2.25 units per $0.75 \mathrm{ml}$ of serosal volume (Table VI, Iigures $4,5, \epsilon)$.

${ }^{1}$ Experiments were run using two or three different insulin concentrations for each segment of the intestine on the same day. They were repeated using the same insulin concentrations on different days. This procedure was generally followed when working with sexually immature rats as it was when working with adult rats. 
TABLE $\mathrm{V}$

EFFECTS OF INSULIN ON L-ALANINE ABSORPTION IN

SEXUALLY MATURE MALE RATS

\begin{tabular}{|c|c|c|c|}
\hline $\begin{array}{l}\text { Insulin concen- } \\
\text { tration* }\end{array}$ & $\begin{array}{l}\text { Effect } \pm \text { S.E. }(\#)^{* *} \\
\text { in duodenum }\end{array}$ & $\begin{array}{l}\text { Effect } \pm \text { S.E. }(\#)^{* *} \\
\quad \text { in jejunum }\end{array}$ & $\begin{array}{l}\text { Eefect } \pm \text { S.E. }(\#)^{* *} \\
\text { in ileum }\end{array}$ \\
\hline 0.1 & $-0.004 \pm-(1)$ & - & $-0.28 \pm 0.04(3)$ \\
\hline 0.5 & $-0.16 \pm 0.04(3)$ & $-0.07 \pm 0.01(5)$ & $-0.14 \pm 0.04(8)$ \\
\hline 1.0 & $-0.14 \pm 0.04(4)$ & $+0.10 \pm 0.01 \quad(5)$ & $-0.08 \pm 0.04(7)$ \\
\hline 1.5 & $-0.04 \pm 0.04(4)$ & $-0.10 \pm 0.01$ & $+0.08 \pm 0.04(8)$ \\
\hline 2.0 & $-0.09 \pm 0.04(4)$ & $+0.05 \pm 0.01$ & $-0.04 \pm 0.04(8)$ \\
\hline 2.5 & $-0.07 \pm 0.04(4)$ & $-0.08 \pm 0.01(6)$ & $-0.10 \pm 0.04(6)$ \\
\hline 3.0 & $+0.08 \pm 0.04(4)$ & $+0.11 \pm 0.01(5)$ & $+0.12 \pm 0.04$ \\
\hline 3.5 & $+0.11 \pm 0.04(4)$ & $+0.14 \pm 0.01$ & $+0.12 \pm 0.04(7)$ \\
\hline 5.0 & $-0.12 \pm 0.04(4)$ & $+0.10 \pm 0.01$ & $-0.06 \pm 0.04(8)$ \\
\hline 10.0 & $-0.01 \pm-\quad$ (1) & - & - \\
\hline $\begin{array}{l}\text { Total number of } \\
\text { experiments }\end{array}$ & 33 & 38 & 63 \\
\hline$F$ value & 4.76 & 2.71 & 5.74 \\
\hline$P^{* * *}$ & $<0.005$ & $<0.05$ & $<0.005$ \\
\hline
\end{tabular}

*Insulin $(U / 0.75 \mathrm{cc})$ was placed on the serosal side of the intestine.

* The values of the effects of physiological agents on amino acid absorption were calculated by subtracting algebraically control S/M from experimental $\mathrm{S} / \mathrm{M}$.

S.E.= standard error.

(\#): Numbers in perentheses indicate the numbers of experiments at each insulin concentration.

**P= significance of the difference between the sample means based on the everted beta distribution (46). 


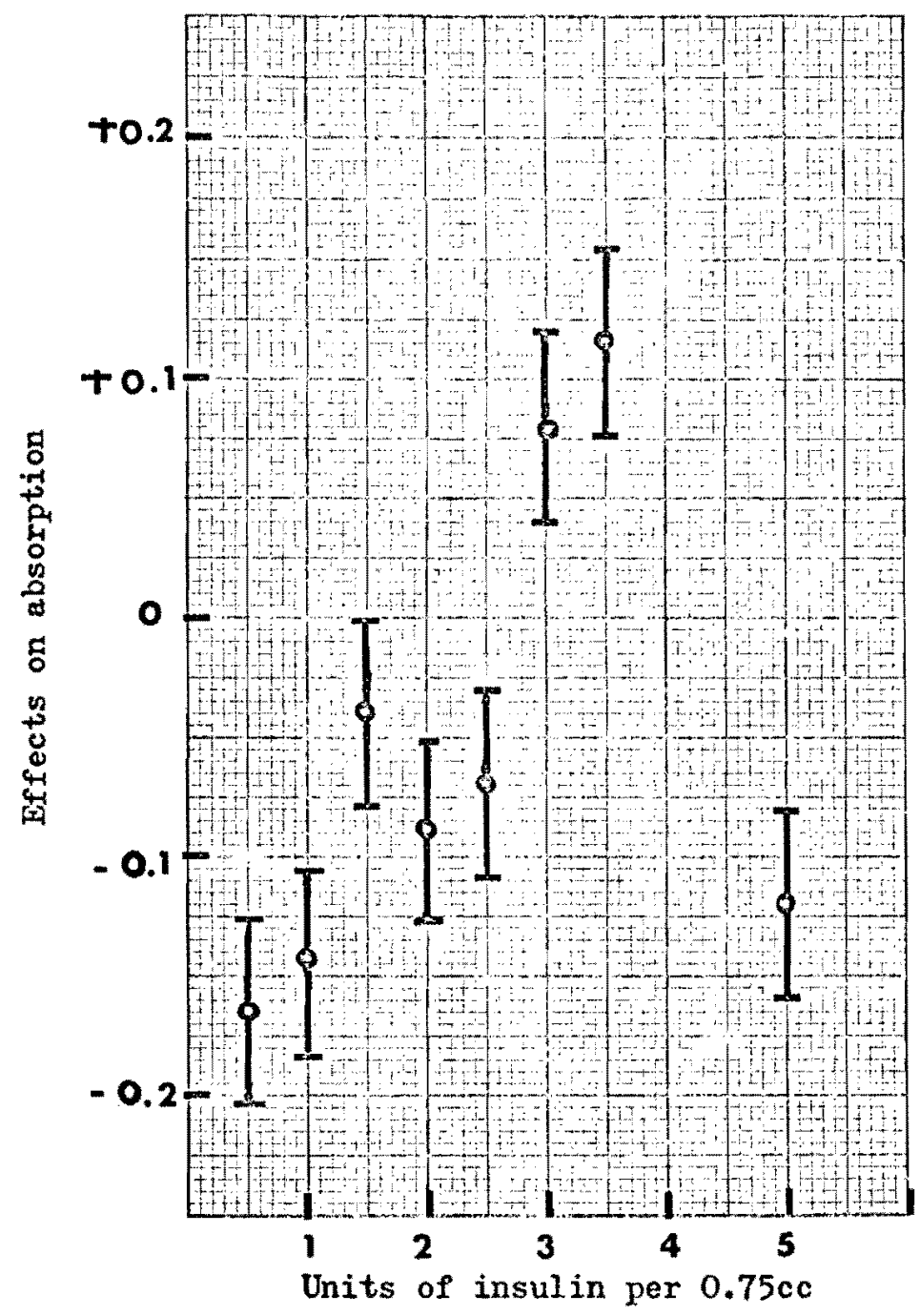

Figure 1. Insulin effects on L-alanine absorption in sexually mature male rats (duodenum). 1

$I_{T h e} S / M$ values of the controls were arbitrarily assigned as the 0 point on the ordinate axis. The effects of insulin were calculated by subtracting algebraically control $\mathrm{S} / \mathrm{M}$ from experimental $\mathrm{S} / \mathrm{M}$. 


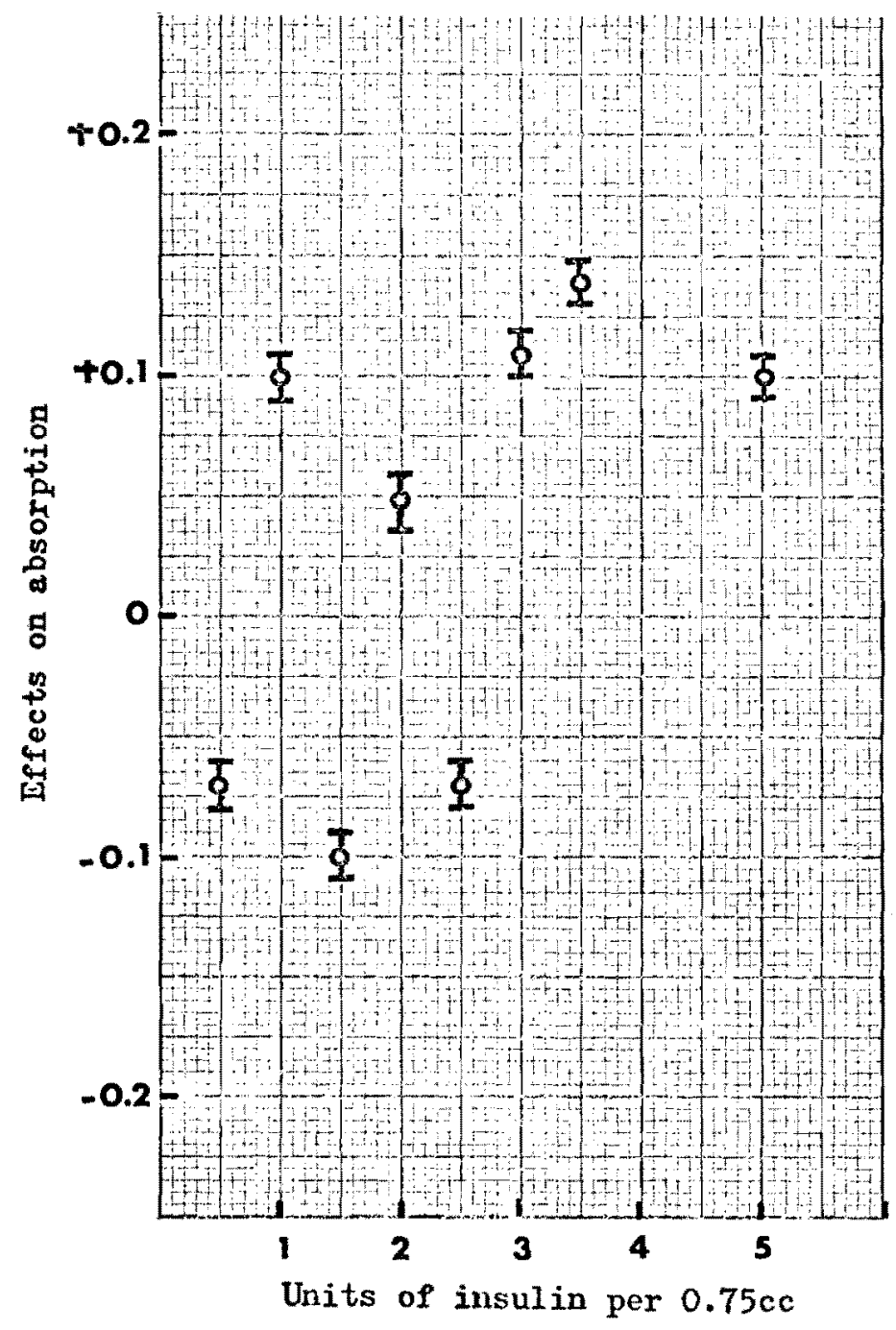

Pigure 2. Insulin effects on L-alanine absorption in sexually mature male rats (jejunum).1

$\boldsymbol{I}_{\text {The }} \mathrm{S} / \mathrm{M}$ values of the controls were arbitrarily assigned as the 0 point on the ordinate axis. The effects of insulin were calculated by subtracting 


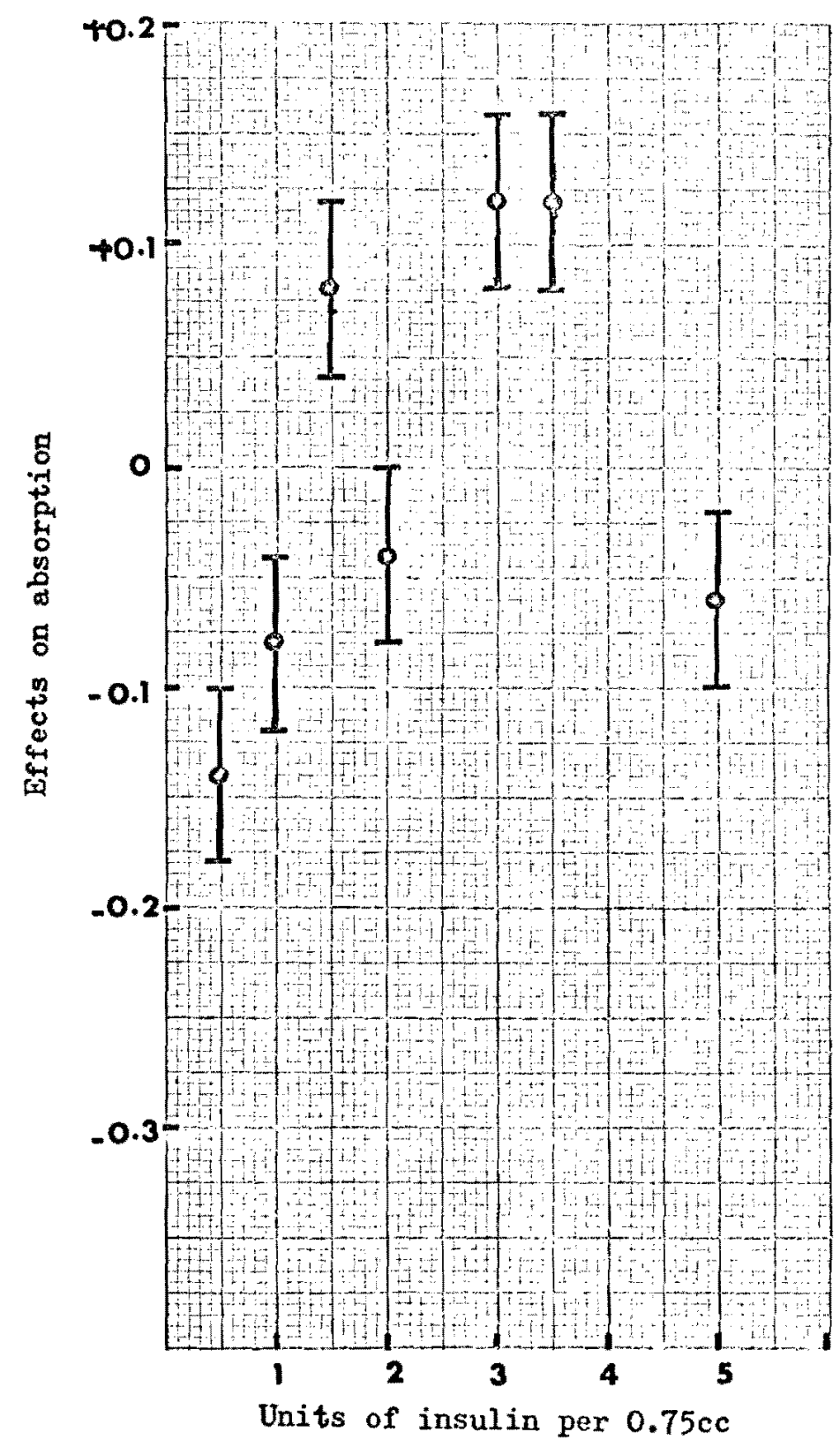

Figure 3. Insulin effects on L-alanine absorption in sexually mature male rats (ileum).1

$1_{\text {The } S / M}$ values of the controls were arbitrarily assigned as the 0 point on the ordinate axis. The effects of insulin were calculated by subtracting algebraically control $\mathrm{S} / \mathrm{M}$ from experimental $\mathrm{S} / \mathrm{M}$. 
TABLE VI

EFFECTS OF INSULIN ON L-ALANINE ABSORPTION IN SEXUALLY IMAATURE MALE RATS

\begin{tabular}{|c|c|c|c|}
\hline $\begin{array}{l}\text { Insulin concen- } \\
\text { tration }\end{array}$ & $\begin{array}{l}\text { Effect } \pm \text { S. E. (\#)** } \\
\text { in duodenum }\end{array}$ & $\begin{array}{l}\text { Effect } \pm \text { S.E. }(\#)^{* *} \\
\text { in jejunum }\end{array}$ & $\begin{array}{l}\text { Effect } \pm \text { S.E. (\#)** } \\
\quad \text { in ileun }\end{array}$ \\
\hline 0.75 & $-0.13 \pm 0.05(3)$ & $-0.09 \pm 0.06(2)$ & $-0.26 \pm 0.10(3)$ \\
\hline 1.50 & $+0.04 \pm 0.05(3)$ & $+0.13 \pm 0.06(3)$ & $+0.35 \pm 0.10(4)$ \\
\hline 2.25 & $+0.19 \pm 0.05(3)$ & $+0.26 \pm 0.06$ & $+0.17 \pm 0.10(5)$ \\
\hline 3.00 & $-0.13 \pm 0.05$ & $-0.04 \pm 0.06(3)$ & $+0.13 \pm 0.10(3)$ \\
\hline 3.75 & $-0.19 \pm 0.05(2)$ & $-0.07 \pm 0.06(2)$ & $-0.10 \pm 0.10(5)$ \\
\hline 4.50 & $-0.11 \pm 0.05$ & $-0.11 \pm 0.06(5)$ & $-0.11 \pm 0.10(5)$ \\
\hline 5.25 & $-0.17 \pm 0.05(2)$ & $+0.10 \pm 0.06(3)$ & $-0.22 \pm 0.10(4)$ \\
\hline 7.25 & $-0.07 \pm 0.05(3)$ & $+0.13 \pm 0.06(4)$ & $+0.06 \pm 0.10(4)$ \\
\hline $\begin{array}{l}\text { Total number of } \\
\text { experiments }\end{array}$ & 22 & 25 & 33 \\
\hline F value & 5.93 & 4.09 & 4.00 \\
\hline$P^{* * *}$ & $<0.005$ & $\leqslant 0.01$ & $<0.005$ \\
\hline
\end{tabular}

*Insulin $(\mathrm{U} / 0.75 \mathrm{cc})$ was placed on the serosal side of the intestine.

**The values of the effects of physiological agents on amino acid absorption were calculated by subtracting algebraically control $S / M$ from experimental $\mathrm{S} / \mathrm{M}$.

S.E. = standard error.

(\#): Numbers in parentheses indicate the numbers of experiments at each insulin concentration.

***P= sigaificance of the difference between the sample means based cis the everted beta distribution (46). 


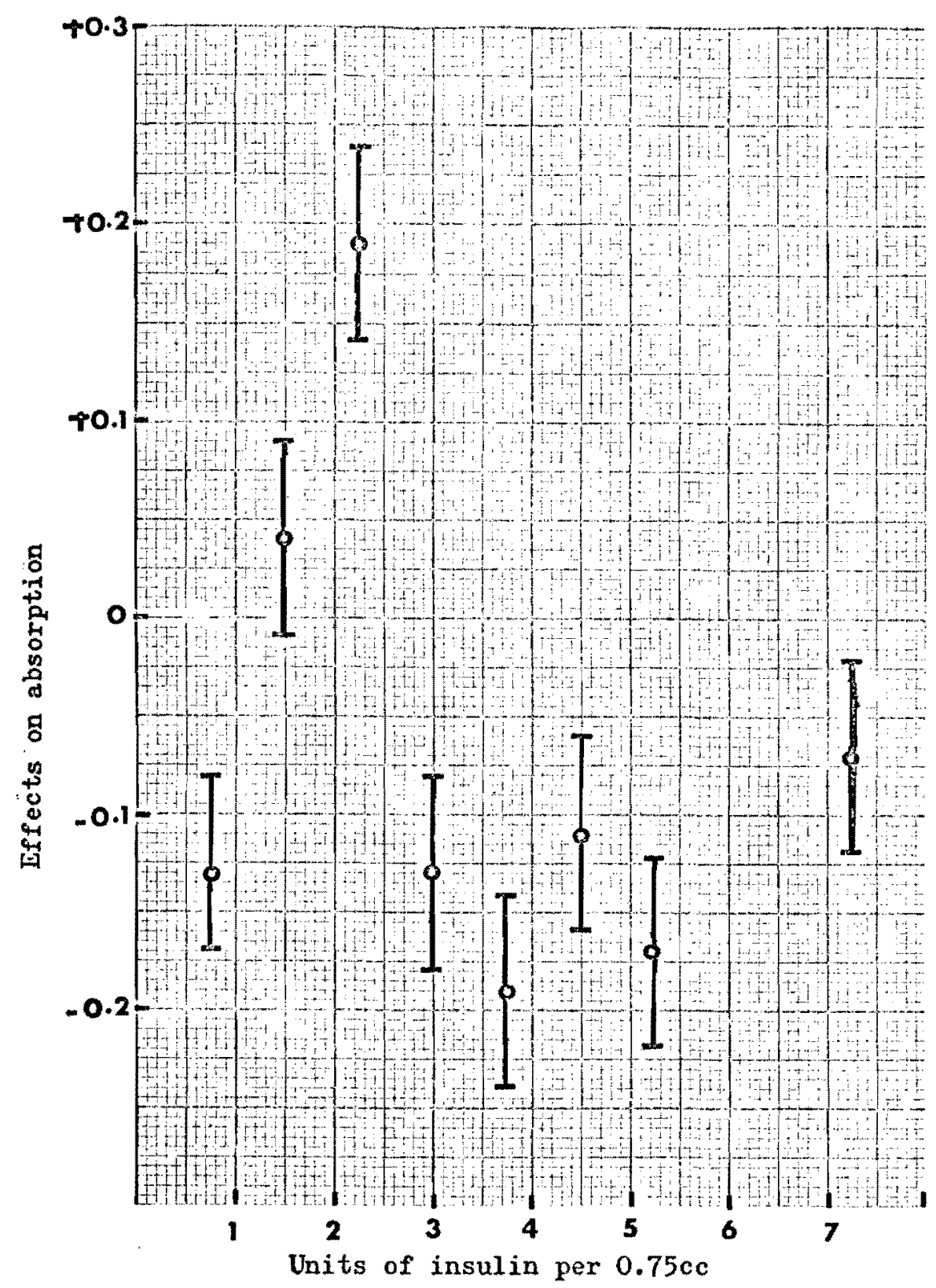

Figure 4. Insulin effects on L-alanine absorption in sexually immature male rats (duodenum). 1

$I_{\text {The }} S / M$ ralues of the controls were arbitrarily assigned as the 0 point on the ordinate axis. The effects of insulin were calculated by subtracting algebraically control $S / M$ from experimental $S / M$. 


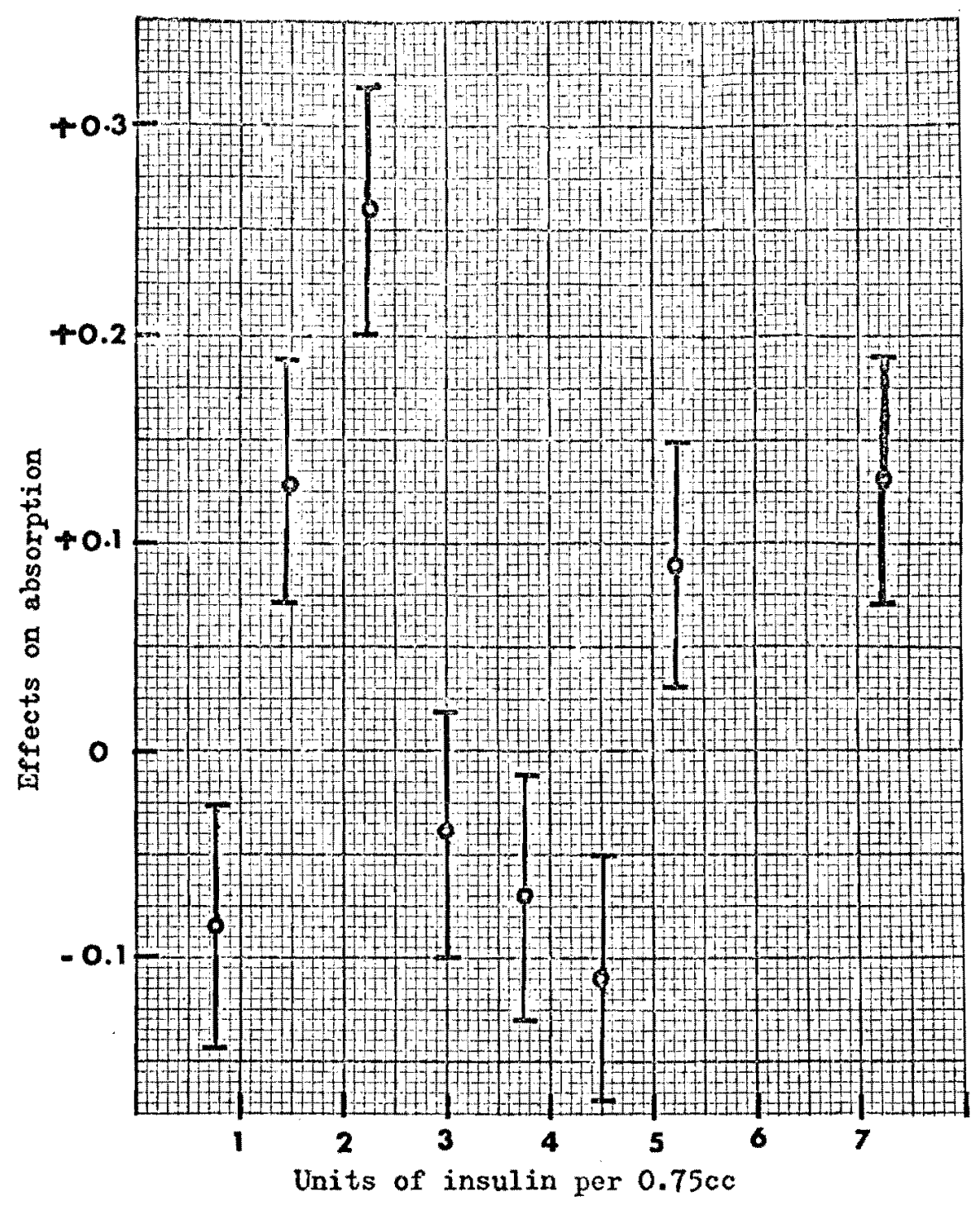

Figure 5. Insulin effects on L-alanine absorption in sexually immature male rats (jejunum). 1

$I_{\text {The }} S / \mathrm{M}$ values of the controls were arbitrarily assigned as the 0 point on the ordinate axis. The effects of insulin were calculated by subtracting algebraically control $\mathrm{S} / \mathrm{M}$ from experimental $\mathrm{S} / \mathrm{M}$. 


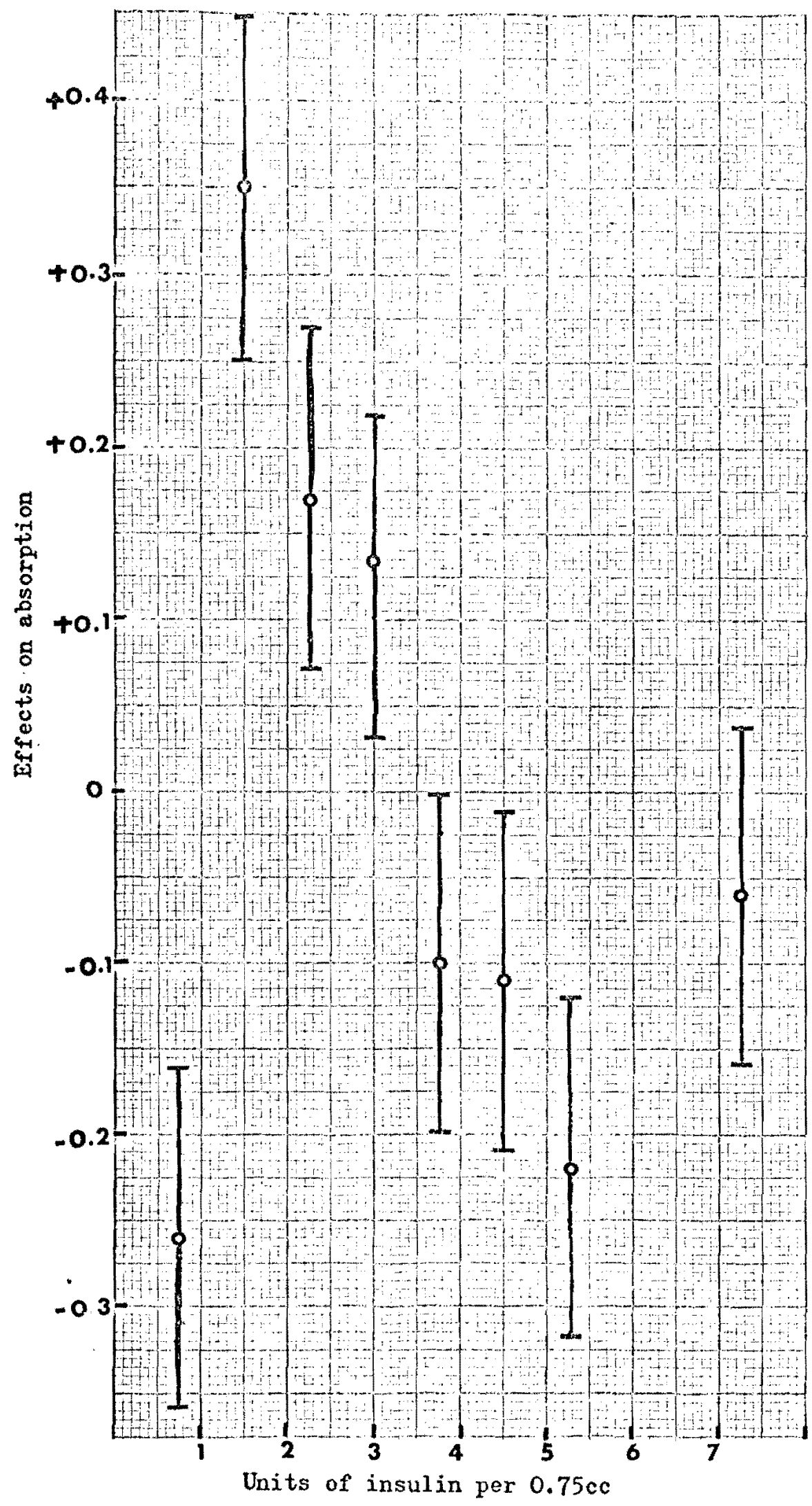

Pigure 6. Insulin effects on L-alanine absorption in sexually immature male rats (ileum). 
L-Alanine Absorption in Sodium-Free Medium

A study was made of the effects of insulin and sodium on rates of amino acid transport.

The first part of the investigation consisted of comparing I-alanine transport through the intestine using a sodium-free Krebs-Ringer's bicarbonate in the sac and in the incubating medium to transport in a normal KrebsRinger's buffer medium. Experimental sacs taken from a given rat were compared to control sacs that were generally taken from the same rat. In most cases, the absence of sodium ions caused a decrease in L-alanine absorption (Table VII).

In the second part of the study, insulin was added to the serosal side and $\mathrm{Na}^{+}$was replaced with $\mathrm{K}^{+}$in the incubating Krebs-Ringer's solution. In the control flasks, a Krebs-Ringer's bicarbonate buffer containing $\mathrm{Na}^{+}$ constituted the mucosal and serosal solutions and no insulin was present on the serosal side of the intestine. Insulin promoted L-alanine absorption in a sodium-free medium (Table VII). 
TABLE' VII

EFFECTS OF SODIUM AND/OR INSULIN ON L-ALANINE

ABSORPTION IN SLXXULLY MATURE MALE RATS

\begin{tabular}{|c|c|c|c|}
\hline & Duodenum & Jejunum & Ileum \\
\hline \multicolumn{4}{|l|}{ Without insulin } \\
\hline $\begin{array}{l}{\left[\mathrm{Na}^{+}\right] \text {in mucosal and }} \\
\text { serosal solutions }\end{array}$ & 0 & 0 & 0 \\
\hline Effect \pm S.E. $(\#)^{*}$ & $-0.17 \pm 0.03(4)$ & $-0.10 \pm 0.04(5)$ & $-0.10 \pm 0.04(8)$ \\
\hline Standard deviation & 0.06 & 0.11 & 0.14 \\
\hline F value & 4.33 & 4.16 & 10.00 \\
\hline $\begin{array}{l}\mathrm{P} \text { (with vs without } \\
\text { sodium ions)** }\end{array}$ & $<0.1$ & $<0.1$ & $<0.01$ \\
\hline \multicolumn{4}{|l|}{ With insulin } \\
\hline $\begin{array}{l}{\left[\mathrm{Na}^{+}\right] \text {in mucosal and }} \\
\text { serosal solutions }\end{array}$ & 0 & 0 & 0 \\
\hline Effect \pm S.E. (保)* & $+0.20 \pm 0.03$ & $+0.08 \pm 0.04(8)$ & $+0.14 \pm 0.04(9)$ \\
\hline Standard deviation & 0.07 & 0.09 & 0.11 \\
\hline F value & 39.93 & 10.09 & 13.89 \\
\hline $\begin{array}{l}\text { P (with vs without } \\
\text { insulin)** }\end{array}$ & $<0.005$ & $<0.01$ & $<0.005$ \\
\hline
\end{tabular}

* The values of the effects of physiological agents on amino acid absorption were calculated by subtracting algebraically control $\mathrm{S} / \mathrm{M}$ from experimental $\mathrm{S} / \mathrm{M}$.

$S_{. E .}=$ standard error.

(H): numbers in parentheses indicate the numbers of experiments.

**P $=$ significance of the difference between the sample means based on the everted beta distribution (46). 


\section{D-Glucose and Amino Acid Absorption}

The effect of D-glucose on L-lysine absorption was studied using a $2.0 \%(\mathrm{w} / \mathrm{v})$ D-glucose Krebs-Ringer's bicarbonate buffer as the incubating medium. The mucosal and serosal Krebs-Ringer's solutions of control flasks contained no glucose and there was no insulin on the serosal side. Absorpm tion in the presence of $\mathrm{D}$-glucose and/or insulin was compared to absorption in these control flasks. In the presence of glucose, there was less absorption of L-lysine. The rate of absorption increased when (glucose being present in the incubating solution) insulin ( $3 \mathrm{U})$ was added to the serosal side of the intestine (Table VIII).

The same type of a study was repeated with a D-glucose concentration of $0.2 \%(\mathrm{w} / \mathrm{v})$. Absorption in the presence of glucose and/or insulin was compared to absorption in a normal Krebs-Ringer's incubating medium (38). At a $0.2 \%$ glucose concentration, less L-alanine was absorbed. However, there was more uptake of the amino acid upon addition of insulin on the serosal side of the intestinal sac (Table IX).

Tables VIII and IX cannot be compared on a quantitative basis since a different amino acid was used in each case. These tables show that $D$-glucose exerts the same qualitative effect on two different amino acids. 
TABLE VIII

EFFICIS OF D-GLUCOSE (2.0\%) AND/OR INSULIN ON L-LYSINE

ABSORPTION IN SEXUALLY MATURE MALE RATS

\begin{tabular}{|c|c|c|c|}
\hline & Duodenum & Jejunum & Ileum \\
\hline \multicolumn{4}{|l|}{ Without insulin } \\
\hline $\begin{array}{l}{[D-g l u c o s e] \text { in mucosal }} \\
\text { and serosal } \\
\text { solutions }\end{array}$ & $2.0 \%(\mathrm{w} / \mathrm{v})$ & $2.0 \%(w / v)$ & $2.0 \%(\mathrm{w} / \mathrm{v})$ \\
\hline Effect \pm S.E. $(\#)^{*}$ & $-0.15 \pm-(1)$ & $-0.06 \pm 0.02$ & $-0.60 \pm 0.10(7)$ \\
\hline Standard deviation & - & 0.02 & 0.73 \\
\hline $\mathbf{F}$ value & - & 4.57 & 3.20 \\
\hline $\begin{array}{l}\mathrm{p} \text { (with vs without } \\
\mathrm{D}-\text { glucose) }\end{array}$ & - & $<0.1$ & $<0.1$ \\
\hline \multicolumn{4}{|l|}{ With insulin } \\
\hline $\begin{array}{c}{[1-g l u c o s e] \text { in mucosal }} \\
\text { and serosal } \\
\text { solutions }\end{array}$ & $2.0 \%(w / v)$ & $2.0 \%(\mathrm{w} / \mathrm{v})$ & $2.0 \%(\mathrm{w} / \mathrm{v})$ \\
\hline Effect \pm S.E. $(\#) *$ & $+0.09 \pm 0.04$ & $+0.12 \pm 0.02(3)$ & $+0.19 \pm 0.10(9)$ \\
\hline Standard deviation & 0.07 & 0.06 & 0.29 \\
\hline $\mathrm{F}$ value & - & 26.40 & 8.05 \\
\hline $\begin{array}{l}\mathrm{P} \text { (with vs without } \\
\text { insulin)** }\end{array}$ & - & $<0.01$ & $<0.05$ \\
\hline
\end{tabular}

* The values of the effects of physiological agents on amino acid absorption were calculated by subtracting algebraically control $\mathrm{S} / \mathrm{M}$ from experimental $\mathrm{S} / \mathrm{M}$.

S.E. = standard error.

(A): numbers in parentheses indicate the numbers of experiments.

**P= significance of the difference between the sample means based on the everted beta distribution (46). 
TABLE IX

EFFICTS OS D-GLUCOSE $(0.2 \%)$ AND/OR INSULIN ON L-ALANINE ABSORPIION IN SEXUALIY MATURE MALE RATS

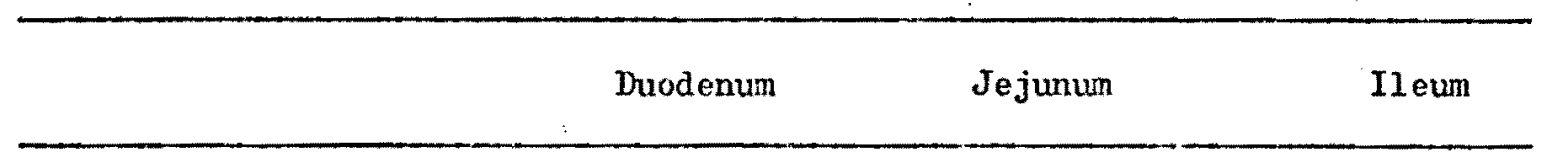

Without insulin

[D-glucose ] in mucosal and serosal solutions

$\begin{array}{rrr}0.2 \%(\mathrm{w} / \mathrm{v}) & 0.2 \%(\mathrm{w} / \mathrm{v}) & 0.2 \%(\mathrm{w} / \mathrm{v}) \\ -0.05(1) & -0.17(1) & -0.07(1)\end{array}$

With insulin

[D-glucose ] in mucosal and serosal solutions
$0.2 \%(w / v)$
$0.2 \%(w / v)$
$0.2 \%(w / v)$

Effect* (\#)**

$+0.01(1)$

$+0.17(1)$

$+0.17(1)$

*The values of the effects of D-glucose were calculated by subtracting algebraically control $\mathrm{S} / \mathrm{M}$ from experimental $\mathrm{S} / \mathrm{M}$.

**(\#): numbers in parentheses indicate the numbers of experiments. 
Error Analysis

Q-Test. Before statistical values were estimated for small samples, a $Q$-test was run on outlying results that were suspected as having occurred as a consequence of some random error. The purpose of this test was to decide whether these border results should be maintained or rejected. This is a statistically valid test that is guaranteed with a $90 \%$ level of confidence (47). 14 out of 484 values (i. e. 2.9\%) were rejected. The rejected values were excluded from the computation of sample means, variances and standard deviations.

Sources of lirrors. The errors that were present in measuring amino acid concentrations by radioactive counting have been sufficiently dealt with (see pages 7,8 , and 9). Other types of errors that could cause some fluctuations in the results are personal errors such as volumetric errors leading to errors in concentrations. 


\section{DISCUSSION}

On Differences in Absorption Potential among the Main Divisions of the

\section{Intestine}

Booth (48) gives a general account on the location of absorption sites of nutrients along the small intestine. He drew a topographic chart which shows that different substances are best absorbed at different intestinal sites. His findings suggest that a given substance is not absorbed at the same rate in all parts of the intestine. The results presented in this paper show that amino acid absorption in the duodenum was slower than in the jejunum and the ileum. But no significant difference was noted between jejunal and ileal transport rates.

Absorption in the Duodenum. Compared to the rest of the small intestine, the duodenum is not a very active site of absorption. Few substances have been shown to be maximally absorbed in the duodenurn in vivo and in vitro $(49,50)$. Therefore, it is not surprising that the experiments showed the least absorption in this segment of the intestine.

Absorption in the Jejunum and the Ileum. Booth (48) remarks that absorption in vivo is in general less active in the ileum than the jejunum, notwithstanding the ability of the ileum to absorb efficiently substances that have escaped absorption in the proximal regions of the intestine. It would then seem that absorption in vivo should be less in the ileum than the jejunum partly because of its distal position. That would be one reason, besides others given by Booth, why "the site of maximum transport by an isolated segment of intestine in vitro may not correspond to its site of 
maximum absorption in vivo." 1

There is a surgical method that might permit one to determine if it is the proximal positon of the jejunum that causes it to absorb more than the ileum in vivo. The procedure involves the removal followed by the reversal of the jejunal and the ileal loops, the jeunum facing the cecum and becoming posterior to the ileum after surgery. If absorption is then maximal in the ileum, the hypothesis, namely that the positon of the post-duodenal segments causes one to absorb more than the other, is true.

The results presented in this paper show maximum in vitro absorption in the upper and middle ileum. Previous in vitro studies have shown that monoaminomonocarboxylic acids are best transported in the middle segments of the small intestine $(39,51,52,53,54)$. If one considers the extreme segments of the adult Fischer rat intestine as being $18 \mathrm{~cm}$ long each, the middle segments make up 40-60 cm covering the jejunum and the upper and middle il eum.

It turned out, as expressed in the data, that the ileum and the jejunum absorbed amino acids at a faster rate than the duodenum.

On the Effects of Insulin upon L-alanine Absorption

In revicwing the literature on intestinal absorption, one normally notices that two procedures are commonly followed: the Wilson-Wiseman evertedsac technique and the tissue accumulation method. The former gives results in terms of the amount of material that is transferred from the mucosal side to the serosal side of the intestine. The latter involves the measurement of substances accunulated in the tissue. Neither process, namely intestinal

${ }^{1}$ c.C. Booth, 1968, "Wffect of location along the small intestine on absorption of nutrients," Handbook of Physiology, 3 (6): 1513-1514. 
tissuc accumalation or transfer from one side to the other, can be said to be intestinal absorption per se since transport is nowmally from the lumen of the intestine through the mucosa into the capillaries.

As insulin was placed on the serosal side of the intestine, it may have exerted its effects on transport in the serosa and possibly in the muscularis. Insulin, being a protein, may have not permeated through all the layers of the intestine. It is then likely that insulin has not come in contact with the mucosa. Fromm et al. circumvented the problem by stripping the small intestine of its serosa and its muscularis. Thus, they assured penetration of the insulin molecule to the basal surface of the mucosa (18). Their model represented a closer copy of in vivo situations than the everted sacs that were used in the present work. In their experiments, indeed, the transmural flux across the intestine could represent a close measure of villi absorption whereas the present investigation measured complete transfer of amino acids from the mucosal to the serosal side of the intestine.

Insulin, according to a standard textbook of medical physiology (55), increases amino acid transport at loast into liver cells and possjbly into other cells as well. Amino acid accumulation into diaphragn $(13,14)$ and heart muscles (17) has been found to be stimulated by insulin (0.1 and $0.2 \mathrm{U} / \mathrm{ml}$ ). However, insulin (persumably $1 \mathrm{U} / \mathrm{ml}$ ) was reported to have no effect on amino acid flux across rat intestine in vivo (18).

The preceding work has not been aimed at a comparison of the effect of insulin on intestinal absorption at different concentration levels. In this paper, however, a range of concentrations varying from 0.1 to 5.0 units of insulin per $0.75 \mathrm{ml}$ of serosal solution was considered. Preparation of dose-response curves secmed valid in light of the variations in response to 
different insulin doses. The graphs (see Figures 1, 2, 3, 4, 5, and 6) show that various insulin concentrations have different effects qualitatively and quantitatively.

Judging from the range of insulin concentrations used in the experiments, this paper describes more a pharmacological situation than a true physiological situation. These concentrations are 100 times (and more) the insulin levels of the plasme of normal rats. Insulin activity of plasma from fasting rats is believed to range from 5 to 30 milliunits per milliliter (56).

On Differences between Insulin Effects upon Adult and Immature Rat

Intestine. A quantitative difference was observed between adult and sexually immature rats as to the effects of insulin on the duodenum and the ileum. The insulin concentration that corresponds to the maximum stimulatory effect on absorption is higher in sexually mature rats (see Figures $1,2,3$, and Figures $4,5,6$, and conpare the peaks of the dose-response graphs for adult rats with those of young rats). At concentrations where a low response was observed in adults, the effects of insulin is relatively strong in sexually immature rats. It should be noted that between adult and 3-4 weeks old rats, there is not only a difference in sexual developnent, but also differences in factors such as body size and mass. The dry weight of a given length of intestine of an adult rat is greater than that of an equal length taken from a 3-4 weeks old (Table X). Quantitative differences observed in the responses of the intestine at the two ages may have something to do with such factors. 
TABLE $X$

DRY WEICHTS OF INTESTINAL SEGMINTS CF A SEXUALLY MATURE AND A SIXXUALIY IMMATURE RAT

Segment source

Segment weight $(216.7 \mathrm{~g}$ mature rat)

Segment weight $(56.2 \mathrm{~g}$ young rat)

and length

$0.198 \mathrm{~g}$

$0.175 \mathrm{~g}$

Duodenum- $12 \mathrm{~cm}$

$0.404 \mathrm{~g}$

$0.283 \mathrm{~g}$

Jejunum-24cm

$0.628 \mathrm{~g}$

$0.360 \mathrm{~g}$

Ileum-36cm

$2.011 \mathrm{~g}$

$0.934 \mathrm{~g}$

Total weight of intestine*

*The sum of the first 3 weight values for each animal is less than the total weight of the whole intestine because the 3 segments weighed do not represent the full length of the intestine. 
On the Effect of Sodium upon L-Alenine Absorption

The results outlined in this paper are in accord with previous experiments which have been conducted on the role of sodium ions in intestinal absorption. It has been demonstrated on several occasions that $\mathrm{Na}^{+}$must be present for substantial amino acid transport across the small intestine $(25,26,27)$. As indirect evidence of the role of sodium, ouabain, a known inhibitor of the sodium pump, reduces L-8lanine uptake in rabbit ileum (57).

Effects of amino acids on sodiun transport have also been studied. Adibi (28) has given evidence of an enhancing action of leucine on sodiun absorption. Nevertheless, he did not see the possibility of a reciprocal action of sodium on amino acid uptake although a previous paper (27) had shown that leucine absorption was a sodium dependent process. Most workers have shown some sort of a facilitation of intestinal absorption of amino acids by sodium ions. Some authors $(25,26,58)$ even see sodium as an essential factor in the active transport of amino acids.

The reason for low L-alanine absorption in the absence of sodium may be due to a lack of activity of the sodium pump. The sodium punp is a poorly understood mechanism. The term refers to the extrusion of sodium ions from cells against the electrochemical gradient. It is therefore a metabolic energy consuming systen. This energy may be applied in the form of a $\mathrm{Na}^{+}$gradient, which is in turn formed at the expense of ATP (59). A similar conclusion was reached by Skou (60). Several workers $(61,62,63)$ have observed $a$ linear relationship between the rate of oxygen consumption and that of tubular reabsorption of sodium in kidneys.

According to Csaky (64), the energy-converting system, that is that part of the transport system which is responsible for the conversion of 
chemical energy into pumping energy, requires intracellular sodium. But intracellular sodium is normally provided by diffusion of external sodium in vitro. Therefore, with no sodium in the incubating solution, intracellular sodium concentration is reduced $(57,64)$ and presumably the activity of the sodium pump decreases with consequent slowing dow of active transport of amino acids.

On the Effects of Insulin upon L-Alanine Absorption in a Sodium-Free Medium Insulin (3U), placed on the serosal side, increases L-alanine absorption whether or not sodium is present. This may be explained by the speculation that insulin is able to alter fine structures of responsive cells causing what Krahl (17) has called decompartmentation. Decompartmentation is a hypothetical sequence of intermolecular rearrangenents that take place in the cell membranes which allows extracellular molecules to enter the cells.

On the Effect of D-Glucose upon Amino Acid Absorption

In considering the effect of D-glucose on intestinal transport of amino acids, one notices that all three possible results have been obtained from previous studies in the literature. Glucose, indeed, has been found to have an inhibitory effect $(33,35)$, a stimulatory effect $(32,34,36)$ and no effect (37).

The results presented in this paper tend to support the view that D-glucose has an inhibitory effect on amino acid transfer across the sinall intestine. It was observed that the addition of D-glucose to the incubating medium caused a sizable decrease of L-lysine absorption. The measurement of D-glucose absorption was not a part of this project. However, there is much 
evidence for the assumption that glucose is actively transported across the intestine $(65,66)$.

There exist possible interactions between the active transport of D-glucose and that of amino acids. It has been suggested that D-glucose inhibits amino acid absorption because the transport of the carbohydrate depends on the same carrier as amino acid transport (31). Such a carrier would be polyfunctional, provided with a series of separate binding sites (66). Lach binding site is thought to be designed for a specific class of compounds, namely sugars, anino acids, electrolytes (31). Conversely, each substance has a certain affinity for its binding site. which causes it to compete with other substances that depend also on the same site. This type of competition may occur between two sugars or two amino acids. Moreover, one substance, by combining with its binding site, may inhibit other binding sites of compounds of different groups by an allosteric mechanism $(32,68)$. Perhaps the effect of D-glucose on amino acid trensport should be classified as allosteric.

This inhibitory effect on amino acid absorption is not peculiar to glucose only. Other actively transported carbohydrates, such as D-galactose, D-allose, 3-0-methyl-D-glucose, also cause intestinal transport of amino acids to decrease (31). D-fructose, L-sorbose and 2-deoxy-D-galactose, sugars which are not actively transported, have been reported to have no inhibitory effect on the absorption of certain amino acids including I-alanine and L-lysine $(30,31)$. 
On the Effect of Insulin upon Anino Acid Absorption in the Presence of D-Glucose

The effect of $D$-glucose on amino acid absoxption hes received more attention in the literature than the combined effect of insulin and D-glucose. Kipnis and Noall (12) found that insulin $(0.40 / \mathrm{nl})$, in the presence or the absence of D-glucose, induced a 3-5 fold increase of $\alpha_{\text {-anino- }}$ isobutyric acid incorporation in the isolated diaphragm of the rat. other papers have shown the independence of the stimulatory effect of insulin $(0.1,0.2,0.5 \mathrm{U} / \mathrm{ml})$ on rat diaphragn from $\mathrm{D}-\mathrm{glucose}(14,69,70)$. The results presented in this paper suggest that the small intestine, in the presence of D-glucose, respond to insulin in a similar fashion to the diaphragm.

The stimulatory effect of insulin is not understood. Several mechanisms, however, have been suggested. By the process of decompartmentation, some pores may have been enlarged or formed by molecular rearrangements in the cell membranes of the intestine. As a result, amino acid trensport, in the presence or the absence of D-glucose, may have been made easier.

\section{On Osmosis}

Osmosis did not appear to be significant in these experiments on absorption. The final serosal and mucosal volumes were sometimes measured and compared with their respective initial volumes. Water absorption ranged from $0 \%$ to $0.5 \%$.

Investigation on osmosis was limited in the course of this research work. However, an analysis of the osmotic conditions of the serosal and the mucosal volumes showed that the two solutions differed on the average by 0.66 micromole of $\mathrm{HCl}$ (the insulin diluent) per milliliter of the serosal 
solution and $1.3 \times 10^{-3}$ micromole of the amino acid per milliliter on the mucosal side. It can be seen, by a simple subtraction, that the serosal side of the intestine was hypertonic to the mucosal side by 0.658 micromole of $\mathrm{HCl}$. Such a minute concentration of hydrogen and chloride ions did not significantly offset the osmotic equilibrium and did not cause water flow from one side to the other. 


\section{CONCLUSTON}

These experiments indicate that the rate of absorption of L-alanine, L-lysine and $\alpha$-aminoisobutyric acid is greater in the ileum and the jejunum than the duodenum. However, amino acid absorption in all three intestinal segments showed generally a similar response to physiological agents such as insulin sodium and D-glucose.

A dose-response effect vas determined for the pancreatic hormone, insulin. The graph of insulin effect versus its concentration on the serosal side followed similar patterns in the main divisions of the intestine: a rise, as the concentration of insulin increases, from inhibition to low stimulation to a maximum enhancing effect.

Amino acid absorption was inhibited in a sodium-Pree medium. It is suggested that such hindrance was caused by an inhibition of sodium pump activity on which amino acid transport is dependent.

Absorption of the amino acids L-alanine and Lmlysine was inhibited by the presence of D-glucose in the incubating solution. This is thought to result from competition between amino acids and sugars for a comon carrier.

It is to bo hoped that more research involving autoradiography, electronmicroscopy and other sophisticated modern techniques can be made on the response of cell membranes to insulin in order to shed more light on the mechanism of insulin action. These techniques may also be important in providing more information on the nature of the sodium pump and on the interactions between sodium, carbohydrates and amino acids in transport processes. 
REFERENCES CITED

1. Davenport, H.W. 1969. Fhysiology of the Digestive Tract. Fearbool Medical Publishers Inc. Chicago. Chapter 16: 192.

2. Ibid. p. 195.

3. Guyton, A.C. 1968. Textbook of Medical Physiology. H.B. Saunders Company. London. p. 909.

4. Ibid. p. 911 .

5. Davis, R.P. 1969. Biological and metabolic aspects of transport. In Biological Membranes. R.M. Dowben ed. Little, Brom and Company. Boston. pp. 109-156.

6. Rosenberg, T. 1948. On accumulation and active transport in biological systems. I. Thermodynamic considerations. Acta Chem. Scand. 2: 14-33.

7. Curran, P.F., and S.G. Schultz. 1968. Transport across membrenes: general principles. Handbook of Physiolory. 3 (6): 1217-1243.

8. Banting, F.G., and C.H. Best. 1922. The internal secretion of the pancreas, J. Lab. and Clin. Med. I: 251-266.

9. Ibid. pp. 464-473.

10. Banting, F.G., C.H. Best, J.B. Collip, J.J.R. Macleod and E.C. Noble. 1922. Effect of insulin on normal rabbits and on rabbits rendered hyperglycemic in various ways. Trans. Roy. Soc. Can. 16 (5): 1-18.

11. Macleod, J.J.R. 1922. Pancreatic extract and diabetes. Can. Med. Assoc. J. 12: $423-425$.

12. Kipnis, D.M., and M.W. Noall. 1958. Stimulation of amino acid transport by insulin in the isolated rat diaphragm. Biochim. Biophys. Acta. 28: $226-227$.

13. Manchester, K.L., and F.G. Young. 1960. The effect of insulin in vitro on the accurnulation of amino acids by the isolated rat diaphragm. Biochem. J. 75: 487-495.

14. Wool, I.G., and M.E. Krahl. 1959. An effect of insulin on peptide synthesis independent of glucose or amino acid transport. Nature. 183: 1399-1400. 
15. Manchester, K.L., and M.E. KrahJ. 1959. The incorporation of $\mathrm{C}^{14}$ from $\mathrm{C}^{14}$-labeled carboxylic acids and bicarbonate into the protein of isolated rat diaphragn. J. Biol. Chem. 234: 2938-2943.

16. Krahl, M.E. 1959. Incorporation of $\mathrm{C}^{14}$-amino acid precursors into adipose-tissuc protein: an insulin stimulation not involving glucose or amino acid transport. Biochim. Biophys. Acta. 35: 556.

17. Krahl, M.E. 1961 The Action of Insulin on Cells. Academic Press. New York and London.

18. Fromm, D., M. Field and W. Silen. 1969. Effect of insulin on sugar and amino acid transport across isolated small intestine. Am. J. Physiol. $217(1): 53-57$.

19. Huxley, A.F.; and R. Stampfli. 1951. Direct determination of membrane resting potential and action potential in single myelinated nerve Pibers. J. Physiol. 112: 476-495.

20. Hogkin, A.L., and B. Katz. 1949. The effect of sodium ions on the electrical activity of the giant axon of the squid. J. Physiol. 108: 37-77.

21. Nastuk, W.L., and A.L. Hogkin. 1950. The electrical activity of single muscle fibers. J.Cell. Comp. Physiol. 35: 39-73.

22. Ussing, H.H. 1948. Transport of ions across cellular membranes. Physiol. Rev. 29: 127-155.

23. Conway, E.J. 1951. The biological performance of osmotic work. A redox pump. Science. 113: 270-273.

24. Conway, E.J. 1953. A redox pump for the biological performance of osmotic work and its relation to the kinetics of free ion diffusion across membranes. Int. Rev. Cyt. 2: 419-445.

25. Csaky, T.Z. 1961. Significance of sodium ions in active intestinal transport of non-electrolytes. Am. J. Physiol. 201: 999-1001.

26. Rosenberg, I.H., A.L. Coleman and L.E. Rosenberg. 1965. The role of sodium ions in the transport of amino acids by the intestine. Biochim. Biophys. Acta. 102: 161-171.

27. Curran, P.F., S.G. Schultz, R.A. Chez and R.E. Fuisz. 1967. Kinetic relations of the sodium-amino acid interaction et the mucosal border of the intestine. J.Gon. Physiol. 50: 1261-1286.

28. Adibi, S.A. 1970. Leucine absorption rate and net movement of sodium and water in human jejunum. J.Appl. Physiol. 28: 753-757. 
29. Hardcastle, P.T., H. Newey and D.H. Smyth. 1968. Factors influencing the effect of glucose on intestinal transport of amino acids. J. Physiol. 196: 33P-34P.

30. Annegers, J.H. 1966. Some effects of hexoses on the absorption of amino acids. Am. J. Physiol. 210 (4): 701-704.

31. Alvarado, F. 1966. Transport of sugars and amino acids in the intestine: evidence for a common carrier. Science. 151: 1010-1013.

32. Nevey, H., and D.H. Smyth. 1964. Effects of sugars on intestinal transpozt of amino acids. Nature. 202: 400-401.

33. Saunders, S.J., and K.J. Isselbacher. 1965. Inhibition of intestinal amino acid transport by hexoses. Biochim. Biophys. Acta. 102: $397-409$.

34. Bingham, J.K., H. Newey and D.H. Smyth. 1966. Specificity of the inhibitory effects of sugars on intestinal amino acid transfer. Biochim. Biophys. Acta. 120: 314-316.

35. Segal, S., S. Thier, M. Fox and L. Rosenberg. 1962. Inhibitory effect of sugars on amino acid accumulation by slices of rat kidney cortex. Biochim. Biophys. Acta. 65: 567-568.

36. Dawson, A.G., H. Newey and D.H. Smyth. 1965. Effect of glucose on different amino acid transfer systens in the rat intestine. Physiol. 179: 56P-57P.

37. Chez, R.A., S.G. Schultz and P.F. Curran. 1966. Effects of sugars on transport of alanine in intestine. Science. 153: 1012-1013.

38. Umbreit, W.W., R.H. Burris and J.F. Stauffer, 1957. Menometric Techniques. Burgess Publishing Co. Minnerpolis, Minn. pp. 147-150.

39. Wilson, T.H., and G. Wiseman. 1954. The use of sacs of everted small intestine for the study of the transference of substances from the mucosal to the serosal surface. J. Playsiol. 123: 116-125.

40. Olsen, W.A., and I.H. Rosenberg. 1970. Intestinal transport of sugars and amino acids in diabetic rats. J. Clin. Invest. 49: 97-105.

41. Nuclear Chicago Corporation. 1966. Liquid Scintillation Counting. Publication No. 711580: 18.

42. Packard Manufacturing Co. Operation Manue 1. Model 314 EX-2 Tricarb Liquid Scintillation Spectrometer System. p. 24.

43. Brown, A.C., and E.J. Masoro. 1965. Absorption from the gastrointestinal tract. Physiology and Biophysics. T.C. Ruch and H.D. Patton, ed. W.B. Saunders Company. Philadelphia and London. pp. 997-1009. 
44. Duncan, D.B. 1955. Multiple range and multiple F tests . Biometrics. $11(1): 1-42$.

45. Fryer, H.C. 1964. Concepts and Methods of Experimental Statistics. Allym and Bacon, Inc. Boston. p. 260-271.

46. Merrington, M., and C.M. Thompson. 1943. iables of percentage points of the inverted beta $(F)$ distribution. Biometrika. 33: 73-88.

47. Skoog, D.A., and D.M. West. 1963. Fundamentals of Analytical Chemistry. Holt, Rinehart and Winston Inc. New York. pp. 58-60.

48. Booth, C.C. 1968. Effect of location on absorption of nutrients. Handbook of Physiology. 3 (6): 1513-1524.

49. Neil, M.W. 1959. The absorption of cystine and cysteine from rat small intestine. Biochem. J. 71: 118-124.

50. Fordtram, J.S., K.H. Soergel and F.J. Ingelfinger. 1960. Intestinal absorption of D-xylose in man. New Eng. J. Med. 267: 274-279.

51. Lin, E.C.C., and T.H. Wilson. 1961. Transport of L-tyrosine by the small intestine in vitro. Am. J. Physiol. 200: 313-317.

52. Matthews, D.M., and L. Laster. 1965. The kinetics of intestinal active transport of five neutral amino acids. Am. J. Physiol. 208: 593-600.

53. iuthans, D., D.F. Tapley and J.E. Ross 1960. Intestinal transport of amino acids studied in vitro with $\mathbf{L}\left(I^{131}\right)$-monoiodotyrosine. Biochim. Biophys. Acta. 41: $271-282$.

54. Spencer, R.P., and A.H. Samiy. 1960. Intestinal transport of L-tryptophan in vitro: inhibition by high concentrations. An. J. Physiol. 199: $\overline{1033-1066 .}$

55. Guyton, A.C. 1968. Textbook of Medical Physiology. W.B. Saunders Company. London. p. 56.

56. Randle, P.J. 1957. Insulin in blood. Ciba Foundation Colloquia on Endocrinology. 11: 115-132.

57. Schultz, S.G., R.E. Fuisz and P.F. Curran. 1966. Amino acid and sugar transport in rabbit ileum. J.Gen. Physiol. 49: 849-866.

58. Bertram, F., and R.A. Nelson. 1970. Sodium dependency of Lmalanine in canine Thiry-Vella loops. Gut. 11: 240-244.

59. Lebninger, A.L. 1970. Biochemistry. Worth Publishers, Inc. New York. . pp. 619-621.

60. Skou, J.C. 1957. The influence of some cations on adenosine triphosphate from peripheral nerves. Biochim. Biophys. Acta. 23:

394-401. 
61. Lassen, N.A., O. Munck and J.H. Thaysev. 1961. Oxygen consumption and sodium reabsorption in the kidney. Acta Physiol. Scand. 51: 371.

62. Deetjen, P., and K. Kramer. 1964. Sodiun reabsorption and oxygen consumption by the kidneys. Klin. Vchnschr. 38: 680 .

63. Tujimoto, M., F.D. Nash and R.H. Kessler. 1964. Effects of cyanide, Qo and dinitrophenol on renal reabsorption and oxygen consumption. Am. J. Physiol. 206: 1327-1332.

64. Csaky, T.Z. 1963. A possible link between active transport of electrolytes and non-electrolytes. Fed. Proc. 22: 3-7.

65. Crane, R.K., D. Miller and I. Bihler. 1961. The restrictions on possible mechanisms of intestinal active transport of sugars. In Membrane Transport and Metabolism. A. Kleinzeller and A. Kotyk, ed. Academic Press. New York. pp. 439-449.

66. Schultz, S.G., and R. Zalusky. 1963. The interaction between active sodium transport and active sugar transport in the isolated rabbit ileum. Biochim. Biophys. Acta. 71: 503-505.

67. Wong, J.T. 1965. The possible role of polyvalent carriers in cellular transports. Biochim. Biophys. Acta. 94: 102-113.

68. Monod, J., J. Wyman and J.P. Changeux. 1965. On the nature of allo1...... steric transitions: a plausible model. J. Mol. Biol. 12: 88-118.

69. Manchester, K.L., and F.G. Young. 1958. The effect of incorporation of amino acids into protein of normal rat diaphragm in vitro. Biochem. J. 70: 353-358.

70. Wool, I.G. 1964. Effect of insulin on accumulation of radioactivity from amino acids by isolated intact rat diaphragm. Nature. 202: 196-197. 
APPENDIX

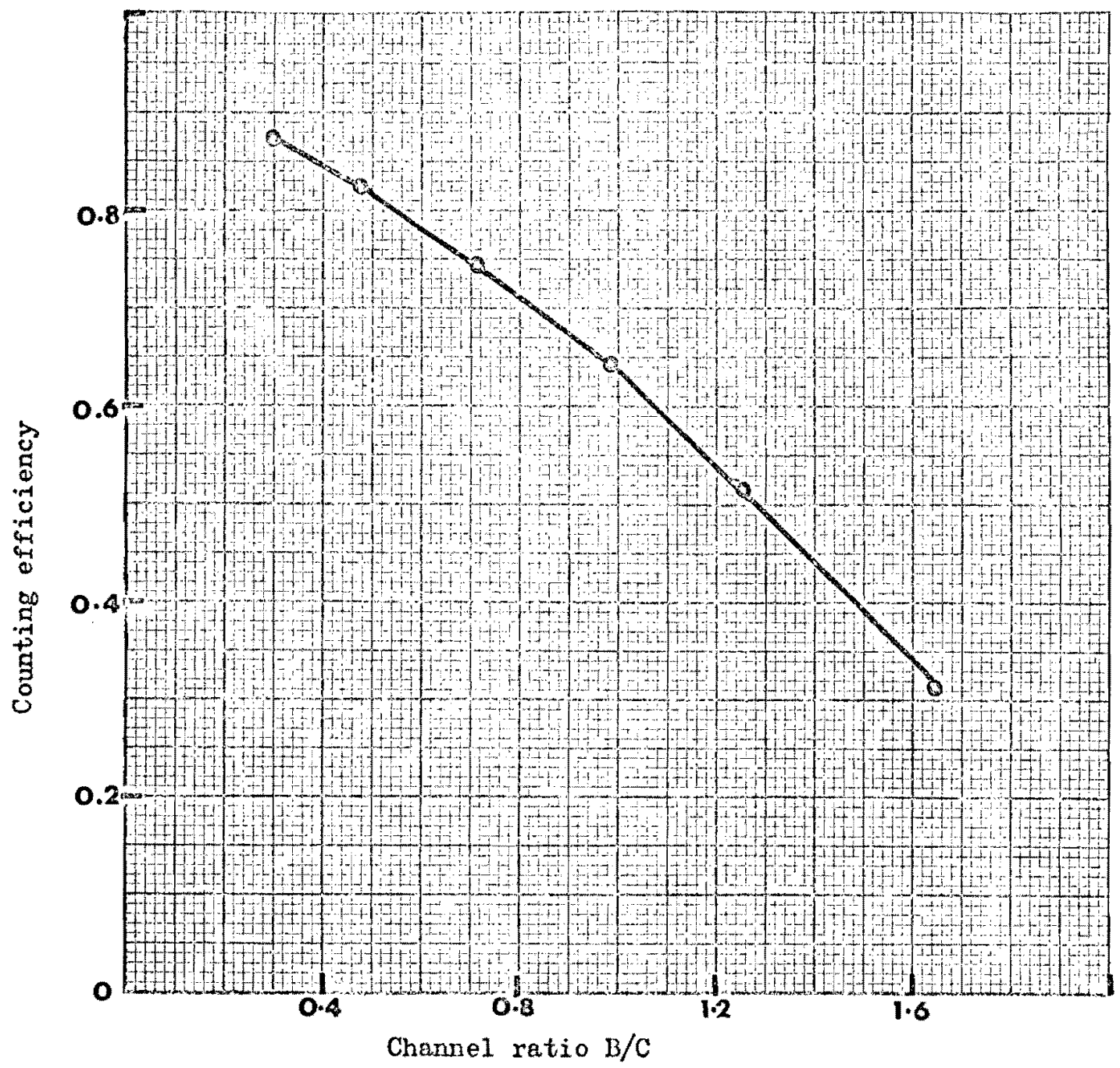

Figure 7. Liquid scintillation counting efficiency as a function of channel ratio. 